\title{
El sistema de gestión de la calidad como aporte para el desarrollo de habilidades y capacidad gerencial en las Pymes de Bogotá
}

\section{Fabio Tejada Losada ${ }^{l}$}

\section{Resumen}

Los sistemas de gestión de la calidad se han convertido en los años más recientes en una alternativa importante para que las organizaciones obtengan una certificación, por parte de un ente certificador, que les permite aumentar las posibilidades de participar en negocios con otras empresas nacionales e internacionales y con entidades del Estado. El problema está en que al concentrarse en este punto focal, el comercial -que de por sí no es contradictorio- las Pymes $^{2}$ no han logrado percibir la importancia que tiene el desarrollo y establecimiento de estos sistemas en la mejora real de la organización, para que, fortalecido su sistema de trabajo, teniendo como soporte los requisitos de una Norma como la NTC ISO 9001:2000, puedan susten-

1 Ingeniero industrial, especialista en recursos humanos; Administrador de empresas, Magister en calidad y gestión integral. Docente investigador en el marco del convenio Universidad Santo Tomás - ICONTEC.

2 Se asume la clasificación de empresa Pyme de la Ley 590/2000 (Pequeña y mediana empresa). tar la rentabilidad, el crecimiento y sostenibilidad de la empresa en el mediano y largo plazo. La forma en que las organizaciones -es decir el cómo-abordan los sistemas de gestión de la calidad al tener como referente primordial la situación comercial que los liga en el corto plazo, es decir, con la intención centrada en responder a una auditoría de certificación o de seguimiento, hace que los aportes de la Norma, al interpretar los requisitos, sean mínimos y terminen por hacer del sistema un problema más con el que las empresas tienen que lidiar, siendo en consecuencia imperceptibles las soluciones que aporta y poco apreciable el beneficio. Uno de los factores que impide tal crecimiento sostenible es la gran debilidad que existe en los cuerpos gerenciales de estas organizaciones, por falta de conocimiento, para generar capacidad de dirección propia que, aplicada a la realidad de la empresa, se convierta en un modelo de gestión más amigable, útil y de alto impacto para los intereses de la organización.

\section{Palabras clave}

Calidad, sistema, gestión, sostenibilidad, gerencia. 


\section{Abstract}

The quality management systems have become the most recent years in an important alternative so that the organizations obtain a certification of a being certifier who allows to increase the possibilities them of participating in businesses with other national and international companies and with organizations of the state. The problem is in which when concentrating itself in this focal point, the commercial one - that of in case he is not contradictory companies Pymes ${ }^{3}$ have not managed to perceive the importance that has the development and establishment of these systems in the real improvement of the organization, so that fortified their system of work, having like support the requirements of a Norm like NTC ISO 9001:2000, can sustain the yield, the growth and sustainability of the company in the medium and long term. The form in which the organizations approach the systems of management of the quality when fundamental referring having like the commercial situation that binds them with the short term, makes that the contributions of the Norm when interpreting the requirements, with the intention centered in responding to a pursuit or certification audit, are minimum and finish making of the system a problem more whereupon the companies must fight, being consequently imperceptible the solutions that contributes and the little appreciable benefit. One of the factors that it prevents such sustainable growth is the great weakness that exists in the managemental bodies of these organizations, by lack of knowledge to generate capacity of own direction, that applied, such capacity, the reality of the company, becomes a model of friendlier, useful management and of high impact for the interests of the organization.

3 It assumes the classification of enterprise Pyme of the Law 590/2000 (Small and medium Enterprise, SME).

\section{Keywords}

Management, quality, system.

\section{ANTECEDENTES}

Desde finales del siglo XIX, cuando se producen los primeros estudios sobre la administración en las organizaciones, ha existido una continua preocupación en el mundo empresarial y sus investigadores por encontrar renovados cómos ${ }^{4}$ que permitan a las empresas aproximarse al logro de los resultados previstos de una forma que asegure su crecimiento, ventaja en el mercado y rentabilidad, al poder hacerlo mejor que la competencia.

La revisión y análisis de las trazas en el conocimiento sobre las organizaciones y en la evolución del pensamiento administrativo nos permite establecer que el $q u e^{5}$ de las organizaciones, siempre ha estado bastante claro, por lo menos en la intencionalidad de la propuesta para el alcance de objetivos y, mediante ellos, la obtención de resultados.

El problema, en mi concepto, ha girado por siempre alrededor de los cómos: Henry Fayol (Francia, 1908) con su teoría general de administración, doctrina administrativa, ciencia administrativa, teoría universalista 0 simplemente Fayolismo; Frederick Winslow Taylor (Estados Unidos, 1880) con la administración científica, racionalización del trabajo o Taylorismo; El sociólogo Max weber (Alemania, 1916) con la teoría burocrática o burocracia; Elton Mayo y su grupo de investigadores en Hawthorne (Estados Unidos, 1927 - 1932), quienes produjeron con su investigación las bases de la

4 Los cómos hacen referencia al conjunto de modelos de administración y de gerencia, métodos de trabajo, herramientas, mecanismos que permiten una gestión eficiente y eficaz de las organizaciones, para lograr resultados tanto económicos como de índole no económica.

5 Los quéestán referidos a la definición de los propósitos y resultados esperados en las organizaciones. 
teoría del enfoque humanístico: organización humana, hombre en la organización o relaciones humanas en la organización, que tiene tantas denominaciones como sub-enfoques en los cuales ha derivado.

Desde tales épocas encontramos información que permite establecer que se viene intentado encontrar explicaciones suficientes, con cuerpos de conocimiento apropiados, para que los negocios se apoyen en renovados cómos que sustenten la actividad empresarial. Cómos que en esta última visión se centran en las personas como factor fundamental para generar mayor productividad. Pensamiento que se ramifica a partir de diversos enfoques, como la calidad total, teoría de las necesidades humanas, desarrollo organizacional, liderazgo, y que llevan a pensar la organización más allá de las máquinas y las actividades de control, como explicación para lograr resultados de mayor eficiencia y eficacia, sacándolas del concepto centrado puramente en la racionalización de las actividades de producción.

La renovada visión desarrollada a partir del enfoque sistémico de las organizaciones propuesta por Katz y Khan (Estados Unidos, 1966), a partir de estudios biológicos que se centran en la célula como el mínimo ser vivo, realizados por el biólogo Ludwig Von Bertalanffy (1935 y 1956), la cual amplía el espectro del análisis empresarial al incluir como aspecto determinante el medio en el cual se mueven y las interrelaciones con ese medio (entorno) que impactan de forma importante el comportamiento del conjunto interno de las organizaciones, que se comportan como seres vivos que no actúan independientes de su medio, lleva a repensar el modelo con el cual hasta ese momento se gestionan las organizaciones.

Posteriormente el fordismo, el toyotismo, la teoría Z Japonesa y otros avances siguen recabando información de experiencias exitosas, que se plantean en su momento como teorías que pasan a engrosar nuevos cómos que buscan sustentar y orientar la capacidad de gestionar las empresas para lograr los "qués" organizacionales.

Los desarrollos posteriores (Joan Wodward, 1965), que tomando la visión sistémica y los avances logrados hasta el momento apuntan más a las contingencias que viven las organizaciones (tecnología - estructura organizacional), llevan a los investigadores a plantear que la incertidumbre que se deriva de la volatilidad de los mercados, el avance tecnológico, tasas de cambio y mercados comercialmente más abiertos, requiere un modelo contingente para la orientación de las empresas.

Éste debe facilitar el gobierno empresarial y mejorar las posibilidades para producir mayor sostenibilidad. Se habla, entonces, con mayor particularidad, de estructura, estrategia, de variables económicas que afectan la conducción de la organización y el diseño de rutas para avanzar con éxito

Toda esta evolución en busca de nuevos cómos organizacionales obliga a apoyarse cada vez más en los avances tecnológicos que comienzan a permitir a las empresas resultados más eficientes.

Se desarrollan modelos matemáticos o modelos estocásticos ${ }^{6}$, apoyados en el desarrollo tecnológico, para fundamentar la toma de decisiones, la administración de costos y el control de los gastos para lograr mayor productividad.

En este interregno se fortalece la visión sistémica en las organizaciones, el ser humano como factor importante -aunque no reconocido- y un enfoque más integrador, que sigue avanzando en la estructuración de cómos que se ajusten cada vez más a las variaciones de la economía, a los avances de la tecnología y de la in-

6 Perteneciente o relativo al azar. Teoría estadística de los procesos cuya evolución en el tiempo es aleatoria, tal como la secuencia de las tiradas de un dado. Biblioteca de Consulta Microsoft@ Encartaß 2005. @ 1993-2004 Microsoft Corporation. 
formación, que permitan a las organizaciones obtener resultados de mayor impacto.

Dentro de toda esta evolución, surge con gran fuerza la calidad como concepto. Busca -el concepto- aportar mayor claridad a las organizaciones para concebir y ejecutar sus operaciones. Dotar a las empresas de orden práctico, que permita su operación eficiente -y posteriormente eficaz-, pero, sobre todo, que asegure mecanismos para mejorar permanentemente.

Se apuesta a una visión menos mecanicista de las organizaciones. A determinarlas y vivirlas en menor grado como una cantidad de actividades que no se relacionan. Por el contrario, apunta más a la totalidad. A una mirada más holística, que sea capaz de producir coherencia dentro de un conjunto de quehaceres bien articulados alrededor de un propósito común. En síntesis, es concebir y vivir más la organización como un sistema.

William Edwards Deming, Joseph M. Juran, Armand V. Feigenbaum, Kaoru Ishikawa y Philip B. Crosby, entre los más importantes, aparecen posicionando, a partir de sus estudios y análisis organizacionales, el concepto de variabilidad y control estadístico de los procesos, de la calidad que se puede asegurar a partir de un control total de las operaciones con herramientas prácticas y suficientes.

En el mundo industrializado, a partir de los anteriores planteamientos y de la evolución propia en la dinámica de las empresas, se fortalece la calidad y se desarrolla un concepto que se orienta a posicionarla como eje nuclear de la actividad organizacional. El concepto avanza y se perfecciona en el desarrollo de sistemas de gestión que asegura que el trabajo se ejecute bajo condiciones controladas.

La calidad -el concepto- avanza desde la inspección de los productos luego de su fabricación; el control estadístico de los procesos debido a su variabilidad para asegurar productos que cumplan con los requisitos especificados; reconocer y controlar el conjunto de procesos que los hace posibles; un enfoque más hacia lo sistémico donde se hace necesario fortalecer la gestión para producir una articulación coherente y el componente humano adquiere mayor relevancia; así las habilidades gerenciales comienzan a ser determinantes, hasta llegar a situar la calidad en un enfoque estratégico. Para obtener, para producir calidad en los productos y servicios, ésta debe concebirse y posicionarse a nivel del pensamiento estratégico de la organización.

Desde ese enfoque humano-estratégico la organización deja de ser el centro de actividad para orientarse a y producir calidad, es decir, la organización deja de ser el fin en sí misma y pasa a verse más como un medio que permite lograr los resultados planificados. El foco, según los expertos, debe estar por fuera del sistema organizacional. El foco se coloca entonces en el mercado y particularmente en los clientes y consumidores, que son los que en últimas toman la decisión de adquirir el producto o utilizar el servicio que ofrece la empresa.

A partir de ese enfoque se robustecen los sistemas de trabajo para asegurar el surgimiento de la calidad. Se comienza a manejar el concepto de gestión y de gerencia como un paso más allá de los puros elementos administrativos. Se reconoce que administrar las actividades sigue siendo importante, pero empieza a ser insuficiente. Se vigoriza entonces, la orientación hacia los sistemas de gestión de la calidad, fundamentados en la familia de Normas ISO 9000, EFQM y otros enfoques, como modelo gerencial mejor estructurado que es capaz de asegurar resultados organizacionales satisfactorios con un alto impacto en la satisfacción del cliente.

Tal perspectiva requiere para su desarrollo efectivo el decidido compromiso de la alta dirección y la participación de toda la comunidad empresarial. 
Entre tanto, en Colombia, la incipiente industria nacional, comienza a configurarse a partir de modelos de administración que se derivan en su totalidad de las investigaciones y avances no precisamente en esta materia, que surgen, principalmente, en Europa y Norteamérica.

La planeación estratégica, la administración por objetivos, los conceptos de la administración científica, las orientaciones de la doctrina administrativa y hasta del modelo burocrático. La teoría humanista en las organizaciones y los enfoques cibernéticos, por mencionar algunos, aparecen entremezclados en las empresas nacionales como una masa uniforme que pretende garantizar con su aplicación resultados que fortalezcan las organizaciones.

A su vez, las universidades del país copian los modelos de administración para transmitirlos a sus estudiantes, sin mayor análisis del contexto en el cual van a tener aplicación.

Todo este maremágnum de puntos de vista entrecruzados provenientes de la copia indiscriminada, de distintos modelos de gestión provenientes de otras culturas, por supuesto, no arrojan los resultados esperados que permitan vigorizar la gerencia de las empresas nacionales. Por el contrario, produce, más bien, un alto nivel de confusión y de desenfoque organizacional.

Resulta incómodo que durante más de 40 años, nuestra experiencia en el campo de la Administración en Latinoamérica, no haya generado un modelo propio de organización empresarial e institucional que nos permita estar a salvo de las oleadas de la "pasarela de las recetas gerenciales, empresariales e institucionales"?

7 Calvo Aguilar, Carlos. Generemos modelos propios. En: Revista digital Mercadeo.com, septiembre 15 de 2006. Consultado: octubre 16 de 2006. Disponible en: http://www.gestiopolis.com/canales6/ $\mathrm{mkt} / \mathrm{mercadeopuntocom/neoadministracion-y-modelos-de-admi-}$ nistracion.htm.
Ha sido víctima la gerencia colombiana de una importación de información que no ha posibilitado el desarrollo de un modelo apropiado de gestión para nuestra cultura empresarial. Las Pymes, desde luego, no han sido ajenas a este fenómeno, recibiendo el impacto con mayor contundencia. Con un agravante, que la mentalidad cortoplacista de quienes han orientado nuestras empresas toman y desechan tales modelos como quien decide cambiar de traje.

No tenemos o no hemos tenido ninguna defensa frente a esta penetración del boom librero de las "recetas de moda" y lo grave no es la oferta, que a fin de cuentas es una actividad legítima, sino la demanda indiscriminada por todo lo "nuevo" y lo "foráneo" para diferenciarnos a lo interno, realidad que es aplastante en nuestro querido continente hispano hablante ${ }^{8}$.

Tal demanda indiscriminada por modelos ha producido un efecto perverso en las empresas nacionales que ha generado escepticismo en las Pymes, y se puede apreciar que no han avanzado en perfeccionar modelos propios que les permitan mayor capacidad y claridad para un adecuado gobierno organizacional.

Un sistema de gestión de la calidad, bajo los lineamientos de la NTC ISO 9001/2000, es una herramienta de administración que ha demostrado ser bastante útil en las empresas que la aplican. Tal utilidad se evidencia más cuando las organizaciones interpretan de forma adecuada y práctica los requisitos, pero, sobre todo, cuando identifican que su construcción es todo un proceso que demanda un alto sentido de responsabilidad de la alta dirección y un fuerte compromiso en todos los estamentos de la empresa.

Es un proceso de transformación organizacional que toca profundamente los cimientos de la cultura del trabajo. En consecuencia, será de mayor impacto en

$8 \quad$ Ibid. 
la medida en que la gerencia tenga capacidad de apropiarse de los elementos intrínsecos del sistema, de interpretar y construir su propia realidad, para derivar en un modelo propio y apropiado de administrar y gestionar la empresa.

La vocación estratégica por desarrollar el sistema a partir de la confluencia de los propósitos de la organización, de los requisitos (explícitos e implícitos) de clientes y consumidores, de los requisitos legales y de los de la Norma, se orienta a construir de forma sistemática un arreglo organizacional que desarrolle capacidad para producir resultados que satisfagan esos requisitos, necesidades y expectativas, pero que también potencialice la capacidad de la empresa para lograr sus objetivos.

\section{LA INVESTIGACIÓN}

Teniendo en cuenta el marco planteado en los antecedentes y con el propósito de desarrollar conocimiento pertinente que permita conocer el efecto que el Sistema de Gestión de la Calidad ha podido producir 0 no en las Pymes de Bogotá, en cuanto a la generación de habilidades gerenciales que faciliten su gestión y dirección, se abordó la investigación tomando como referente tres organizaciones certificadas con la Norma NTC ISO 9001/2000 pertenecientes a la categoría de Pyme, de diferentes sectores -educativo, artes gráficas y metalmecánico-, en las cuales se entrevistó a sus gerentes y a trabajadores de diferentes niveles para recopilar y analizar información a partir de sus realidades.

Luego de consultar con expertos en el tema de la gerencia y la calidad-gerentes, docentes, consultores-se seleccionaron nueve (9) categorías que, en su concepto, son los que más apalancan y nutren la capacidad de gobierno de una empresa e incrementan las posibilidades de un negocio para alcanzar resultados exitosos sostenidos.
Se tienen en cuenta además los factores que desde las Normas para la gestión de la calidad se consideran como determinantes para una gerencia adecuada de organizaciones, lo que confluye en la rentabilidad, crecimiento y sostenibilidad, que fortalecen la gerencia y su gestión a partir de la implementación y mantenimiento de un Sistema de Gestión de la Calidad, éstas sirvieron al investigador de punto focal para el análisis y conclusiones sobre la materia.

La investigación se orientó en una perspectiva histórica-hermenéutica-analítica, donde se sigue la pista a la realidad del aporte de un Sistema de Gestión de la Calidad en la capacidad gerencial para explicarla y para llegar a generalizaciones. Pero, igualmente, permite comprender e interpretar significados al interior de las Pyme, para que a partir de este aporte ellas puedan orientarse de una manera efectiva en el mundo de los negocios, cada vez más globalizado.

Las categorías determinadas para la investigación, recogen los aspectos importantes necesarios para asegurar la eficacia gerencial de un sistema de gestión de la calidad que vaya más allá del cumplimiento mínimo de los requerimientos de la norma y contribuya al desarrollo de capacidad de gestión en las Pyme investigadas.

Como técnica originaria se utilizaron entrevistas sociológicas a profundidad, semi-estructuradas, dirigidas a la gerencia de las empresas seleccionadas para la investigación. La relación con el entrevistado es totalmente asimétrica. Se utiliza el método de saturación de la información obtenida en las entrevistas, que permite la determinación de una muestra suficiente.

Se complementó el aspecto tecnológico con encuestas, preguntas - respuestas (perspectiva distributiva), que se aplicaron a los trabajadores de niveles diferentes al de la gerencia de la organización para identificar si desde la perspectiva cultural de los miembros de la 
empresa en general se tiene claridad sobre la adopción de modelos de gestión y administración, a partir de la práctica gerencial, que hayan posibilitado y facilitado su concurso para vincularse de manera más efectiva a los logros organizacionales.

Se relacionó el análisis extraído de la información gerencial en las entrevistas con el análisis estadístico de la información general de la empresa recopilada de la manera descrita, en las encuestas, por cada categoría en el informe de investigación, en un proceso de contrastación, como estrategia de validación de la realidad de la organización frente al objeto de la investigación (perspectiva predictiva, análisis entre variables cuantitativas y cualitativas).

Es decir, si tanto en el pensamiento de la gerencia como en la vivencia de los trabajadores se percibe y se puede evidenciar que han surgido, a partir de la implementación del Sistema de Gestión de la Calidad, habilidades y capacidad de gestión por parte de la gerencia en las Pymes investigadas.

El aspecto ético de la investigación se orientó al proceder ético del investigador y a que ella, la investigación, no estuvo determinada por un interés particular diferente al de producir conocimiento sobre la realidad gerencial de las Pymes seleccionadas, de tal forma que tal conocimiento sea pertinente y útil para este sector productivo de la economía Nacional, así como para la academia colombiana.

\section{CATEGORÍAS QUE FORTALECEN LA GERENCIA A PARTIR DEL DESARROLLO DE UN SISTEMA DE GESTIÓN DE LA CALIDAD}

Para enfocar de forma más adecuada el tema, se profundiza sobre los factores que permiten rescatar las variables que desde la implementación de un Sistema de Gestión de la Calidad, bajo la Norma NTC ISO 9001/2000, con apoyo en la NTC ISO 9000/2005 y NTC ISO 9004/2000, debieran ayudar a la Gerencia a construir mayor solidez en la gestión de las empresas y producir un impacto en el sistema o modelo para orientar los negocios, que aseguren apropiados métodos de conducción y de gobierno empresarial.

Estas categorías son las que se tienen en cuenta para realizar la entrevistas con los gerentes de empresas y establecer cómo, en la realidad de las organizaciones, han venido siendo aplicadas y el efecto que han producido en la capacidad de gestión del negocio.

Igualmente, son las mismas categorías por las que se indaga a través de encuestas al personal de las organizaciones de los gerentes entrevistados, para tener una apreciación organizacional completa de la concepción y práctica gerencial y de la percepción de los trabajadores encargados de cumplir con diversas actividades al interior de los procesos y de las empresas.

No se pretende, pues, presentar estas categorías en su conjunto como un modelo de gestión, ni de manera exhaustiva, sino de realizar su elaboración conceptual y teórica, como estado del arte, que permita lineamien- 
tos para afianzar las conclusiones de la investigación. Aproximarse a ellas para entender los cómos que fortalecen la gestión de una organización, como efecto de la implementación de un sistema de gestión de la calidad.

\section{A. Planeación estratégica}

Es concebida como la definición y estructuración de la plataforma fundamental para la empresa, que sirve de guía para encauzar y alinear los esfuerzos, la energía de la organización y focalizarla en un horizonte concreto. El arte y la ciencia de formular, implantar y evaluar las decisiones a través de las funciones que permitan a una empresa lograr sus objetivos?.

Los planes que define la organización en directa relación con la estrategia determinada para el negocio, de tal manera que la empresa y la gerencia concentren su acción en los objetivos que puntualiza como los "crucialmente importantes" ${ }^{10}$.

"La estrategia es un plan enfocado en el mercado que ayuda a darle a la empresa una ventaja competitiva sobre sus competidores a través de la diferenciación. El patrón de decisiones que intencionalmente establecen la dirección de la organización a largo plazo y determinan su destino" (apuntes de clase de de la asignatura Gerencia estratégica, orientada por el Dr. Orlando Salinas, de la Maestría en Calidad y Gestión Integral, julio 27 de 2007).

El marco conceptual que se toma para esta categoría es el expresado anteriormente, que está dentro del contexto de la matriz de categorías establecida para la investigación.

La gestión de la organización, en su concepción más avanzada, se apoya en la precisa definición y estructu-

9 DAVID, Fred R. Conceptos de administración estratégica. Novena edición. Editorial Pearson. Prentice Hall. México 2006.

10 Cover, Stephen R. Primero lo primero. Barcelona: Paidós, 1996. ración de un plan estratégico que facilita a la gerencia orientar los diferentes componentes del negocio de manera alineada, evitando la dispersión de esfuerzos que mantiene a las personas de los diferentes procesos muy ocupadas pero altamente improductivas.

Es determinante que la gerencia construya de manera precisa, clara y participativa la plataforma compuesta por planes estratégicos, que consultando la realidad de un mercado cada vez más volátil y su capacidad interna, sirva para que las personas de la organización puedan conectar su realidad de trabajo con los propósitos fundamentales establecidos por la organización.

En consecuencia, esta plataforma tiene que ser concebida en y para la organización, evitando la tentación de llenarla de una cantidad de elementos y detalles de la parafernalia administrativa tradicional, para que se pueda traducir en planes operativos y tácticos sencillos y precisos; visibles, identificables y aprehensibles; medibles y alcanzables por parte de la comunidad organizacional.

Un sistema de gestión de la calidad requiere que haya claridad, precisión y entendimiento pertinente de tal plataforma estratégica en los niveles estratégicos, tácticos y operativos del negocio, pues es la que permite crear sentido práctico y responder permanentemente a la pregunta del por qué y para qué mantengo y mejoro mi sistema de gestión.

En sentido contrario, un sistema de gestión de la calidad, como cualquier otro sistema de gestión, queda desamparado y huérfano si la empresa no cuenta con un horizonte estratégico y, como suelo expresarlo permanentemente, sería construir sobre el vacío, pues no tengo de donde "colgar", de donde "enganchar" el sistema de gestión de la calidad.

La NTC ISO 9001/2000, en su numeral 0.1, manifiesta: "La adopción de un sistema de gestión de la calidad debería ser una decisión estratégica de la organiza- 
ción”. Plantea de entrada que las organizaciones deben ocuparse de la estrategia y que un Sistema de Gestión bajo sus lineamientos, para producir calidad, debe estar íntimamente ligado con la plataforma estratégica del negocio. Esto facilita la generación de valor para la empresa, los dueños, los accionistas, los colaboradores, la comunidad y, lo más importante, los clientes que demandan los productos o servicios que produce.

Desde luego este direccionamiento estratégico debe ser elaborado de manera realista y práctica para la organización, evitando al máximo que se convierta en un problema más a ser administrado. La flexibilidad, así como la perspectiva en el tiempo, cuando se habla de largo, mediano y corto plazo, es vital para que pueda ser entendida y aplicada con alto impacto en los resultados esperados.

El direccionamiento estratégico, generalmente y con algunas variaciones, se encuentra constituido por la misión, la visión, principios, valores, los objetivos fundamentales del negocio, la estrategia (producto de la creación estratégica, en estrecha relación con el ambiente externo y el ambiente interno), los objetivos estratégicos de procesos/áreas, los planes operativos con sus tácticas operacionales y la medición del desempeño con sus indicadores de gestión y por supuesto con los recursos necesarios.

Este factor, como se ve, es determinante para fortalecer la gestión y el gobierno de una empresa. Su construcción, despliegue, buena comunicación, seguimiento y control, entre otros, son responsabilidad directa de la gerencia de la organización. Y es un factor de alto impacto en la gestión que debe verse fortalecido a partir de la implementación de un sistema de gestión de la calidad.

\section{B. Comunicación}

Las organizaciones son una permanente y compleja red de comunicaciones en todos los sentidos y niveles.
Las comunicaciones son el eje articulador que debiera producir un sentido de comunidad y entendimiento alrededor de propósitos, tareas y quehaceres empresariales, sin considerar aquí la comunicación personal y de nivel privado que se da aparejada con la comunicación "oficial", asunto que la hace aún más compleja. Las dos en mi concepto conforman el todo.

Transmitir las ideas de una mente a otras mediante algún tipo de representación es de las cosas más difíciles en el mundo. Ya lo expresaba así Lewis Carroll en "Alicia en el País de las Maravillas".

La comunicación entendida como "el proceso de intercambio de información entre dos o más personas" es uno de los actos indispensables de la vida en sociedad de la humanidad. Es inclusive, uno de los principales pilares de la vida en comunidad, por lo que ha sido motivo de estudio y perfeccionamiento desde los tiempos más remotos de la cultura universal, porque, además, no es un proceso sencillo, simple, si se pretende realizarlo correctamente ${ }^{11}$.

Esta comunicación debe ser entendida y practicada más allá de los elementos tradicionales de un receptor en consonancia con el dial de un transmisor. La comunicación es la interacción simbólica de al menos dos participantes que comparten un código en común y responden en función del estímulo del otro.

A nivel empresarial e institucional, las organizaciones se comunican hacia su interior y con su entorno. La calidad de esa interacción simbólica es un bien intangible que cada vez es más reconocido por las distintas teorías administrativas ${ }^{12}$.

11 Bozzeti, Santiago Luis. Comunicación estratégica. En: www.gestiopolis.com, 2007.

12 Ibid. 
Pero para que dicha calidad sea óptima, la organización no puede darse el lujo de dejar librado al azar o la espontaneidad los mensajes que envía hacia sus distintos públicos. Ser espontáneo, irreverente y hasta contradictorio, puede ser muy bueno para la vida cotidiana de las personas, pero una organización necesita planificar todas sus acciones comunicativas de modo que conserven una coherencia simbólica que guíe hacia los objetivos de la institución ${ }^{13}$.

La gerencia tiene la alta responsabilidad de ocuparse en diseñar un sistema de comunicación al interior de la organización que le permita construir canales efectivos por los cuales "viaje" de ida y de regreso, en todos los niveles de la empresa, comunicación con información pertinente que permita un buen nivel de entendimiento y comprensión de los horizontes del negocio, así como de las responsabilidades y quehaceres en cada uno de los procesos, cargos y oficios de la empresa. Con arreglo a la matriz de categorías, es éste el enfoque que se toma para analizar la realidad de las empresas.

Sin desestimar desde luego, la gestión de los canales de comunicación e información que deben estar permanentemente abiertos para los clientes y usuarios, el mercado, que demanda productos y servicios del negocio.

En consecuencia, la gerencia o alta dirección de la empresa debería definir e implementar procesos de comunicación que aseguren información para producir tal eficacia y eficiencia, en consonancia directa, por supuesto, con los propósitos fundamentales del negocio, la autoridad, la responsabilidad y los quehaceres de cada uno de los participantes en el sistema, quienes ejecutan las diferentes actividades. No hacerlo de esta manera impacta de manera negativa en grado sumo la capacidad de desempeño del sistema y su consecuente mejora.

\section{Organización orientada al cliente}

No es un secreto que la supervivencia de las organizaciones depende directamente de quienes demandan y consumen los productos y servicios que éstas ofrecen al mercado. En consecuencia, la gerencia de una empresa debería focalizar su estrategia y actividades consecuentes en desarrollar capacidad para "conectarse" cada vez mejor con clientes, usuarios y consumidores de sus productos y servicios. Y conocer e interpretar correctamente el mercado en el cual aspira a posicionar su organización en una segunda instancia, en quienes no son sus clientes.

La Norma NTC ISO 9004/2000 recoge esta sentida necesidad en su numeral 5.2.2: "El éxito de una organización depende de entender y satisfacer las necesidades y expectativas actuales y futuras de los clientes y usuarios finales actuales y potenciales, así como de comprender y considerar las de otras partes interesadas".

Dentro de estas partes interesadas es muy importante considerar los miembros de la organización y buscar el desarrollo de una cultura en la dirección para darles un tratamiento de clientes internos. Supone el rompimiento de paradigmas en algunas mentes gerenciales, sin perder de vista que se tiene un solo tipo de cliente al cual se deben volcar todas las energías del negocio: el cliente externo.

En una cultura de calidad la voz del cliente es la voz cantante y sonante. Todo el enfoque de calidad está basado en este principio básico de buena administración. Es más, la definición moderna de calidad es sinónimo de fascinar al cliente, esto es, ofrecer cualidades en el producto (bienes y servicios) entregado, que superen las expectativas y necesidades básicas que tiene el cliente con dicho producto ${ }^{14}$. 
Tal debe ser la ocupación de la gerencia, mucho más cuando se ha establecido un sistema de gestión de la calidad que demanda el fortalecimiento de la gestión del negocio para alcanzar los resultados planificados mediante esta focalización.

Ahora bien, esta focalización se hace más exigente al orientar la organización hacia el cliente, demanda un mayor esfuerzo de la gerencia dado que "es bien sabido que cada vez es más importante la tendencia que el cliente no compra las características intrínsecas de un producto, sino que lo que quiere es cubrir sus necesidades a través de ese producto concreto y todos los servicios y valores añadidos asociados a él.

Por lo tanto, el protagonismo del producto en sí queda diluido como un componente más del valor que se le aporta al cliente. De una manera más concreta, se puede decir que un concesionario de automóviles no es una empresa que vende coches, sino que es una organización que soluciona un problema de transporte y movilidad a sus clientes, mediante un producto concreto que se llama automóvil"15.

Es el reto que tiene la gerencia. Gestionar la organización para orientarla hacia ese punto focal, gestión que debe ser mucho más clara y precisa cuando se ha establecido un Sistema de Gestión de la Calidad.

En esta categoría se toma como patrón conductor el que se deriva de la NTC ISO 9004/2000.

\section{Liderazgo}

Mucho se ha dicho y escrito alrededor del tema del liderazgo, tanto, que ya los conceptos se vuelven difusos y la mayoría de las veces poco aplicables a la realidad. Por lo tanto, se trata aquí de precisar para este

15 Navarro, Eduardo. En: "El cliente en el centro de la empresa". En: Gestióplis.com, abril de 2005. factor que fortalece la gestión de una organización los elementos básicos que concreten el concepto dentro de un Sistema de Gestión de la Calidad. El liderazgo como componente vital para construcción de sentido práctico en el conjunto organizacional, que permita alcanzar los resultados planificados sin dejar a los participantes tendidos en el camino.

Stephen Covey tiene una aproximación al concepto que parece simplista por lo corto de su expresión, pero a la cual le encuentro un gran significado: "Convertir la resistencia en compromiso" ${ }^{16}$. Significado que es mayor cuando se trata de implementar, mantener y mejorar un sistema de gestión de la calidad.

La Norma NTC ISO 9001/200, en el numeral 0.2, expresa que: "Los líderes establecen la unidad de propósito y la orientación de la organización. Ellos deberían crear y mantener un ambiente interno en el cual el personal pueda llegar a involucrarse totalmente en el logro de los objetivos de la organización”.

Por supuesto que todo tiene lugar en el escenario organizacional. Allí es común confundir los elementos de administración con aquellos que son fundamentales para construir un verdadero rumbo en la empresa a partir del convencimiento de la personas. Según John P. Kotter:

La administración es un conjunto de procesos que pueden hacer que un sistema complicado de personas y tecnología funcionen sin problemas. Los aspectos más importantes de la administración incluyen planear, presupuestar, organizar, proveer personal, controlar y resolver problemas. El Liderazgo es un conjunto de procesos que da lugar a organizaciones en primer lugar, o que las adapta ante circunstancias significativamente cambiantes. El Liderazgo define cómo debería ser el futuro, alinea a la gente con esa visión y la inspira para hacerla realidad a pesar de los obstáculos ${ }^{17}$.

16 Cover, Stephen R. El liderazgo centrado en principios. Buenos Aires: Paidós, 1995.

17 Kotter, John P. El líder del cambio. México: Mc Graw Hill, 2000. 
La administración da como resultado un cierto grado de orden y facilidad para vaticinar situaciones y tiene el potencial de producir de manera consistente los resultados a corto plazo.

El liderazgo tiene la capacidad de generar cambio, con frecuencia en un grado importante, y tiene la capacidad de producir cambios excesivamente útiles. Hacer las cosas correctas, correctamente. Se logra lo anterior estableciendo una dirección, creando un rumbo, desarrollando una visión del futuro y la estrategia para producir los cambios y alcanzarlos; alineando la gente transmitiendo la dirección, el rumbo en palabras y hechos, a todos aquellos cuya cooperación pudiera necesitarse para influir en la construcción de equipos y coaliciones que comprendan la visión y las estrategias y que acepten su validez; motivando e inspirando al transmitir energía a la gente para superar barreras políticas y burocráticas y de recursos importantes mediante la satisfacción de necesidades humanas básicas, aunque con frecuencia insatisfechas ${ }^{18}$.

Los autores Dave Ulrich, Jack Zenger y Norm Smallwood reconocen el liderazgo, en personas que dominan ciertas competencias y emanan carácter, pero van más allá de eso, los líderes hacen mucho más que demostrar atributos. Los líderes eficaces consiguen resultados ${ }^{19}$.

En consecuencia, la responsabilidad de la gerencia está en producir un clima, un escenario organizacional en el cual las personas aprecien con claridad el horizonte al que se deben dirigir, el rumbo que deben tomar, las herramientas de la administración para avanzar, con un estilo de orientación y acompañamiento que les permita dar pasos en ese sentido porque aprenden, en-

\section{Ibid.}

19 Ulrich, Dave; Zenger, Jack; Smallwood, Norm. Liderazgo basado en resultados. Bogotá: Norma, 2000. tienden y se convencen de que es importante para la organización y para ellos, que es más productivo alcanzar los resultados sin necesidad de estarlos empujando. Esto toca directamente las fibras de la gerencia para la conducción del negocio.

Se toma en completa articulación con la matriz de resultados los elementos que se derivan de la NTC ISO 9001/2000 y los planteamientos de Kotter y Ulrich ya descritos.

\section{E. Gestión sistémica}

Desde la aparición de la teoría general de sistemas (a partir de los estudios del biólogo Ludwig Von Bertalanffy -1935 y 1956- recogidos por Katz y Khan -Estados Unidos, 1966-), los cómos para administrar las organizaciones cambiaron de una manera radical.

Al dejar de ser consideradas como sistemas cerrados aislados de su entorno y reconocer y aprender que el impacto del ambiente externo en sus interrelaciones con ese entorno produjo una revolución para comprender la naturaleza de los fenómenos organizacionales y en consecuencia las habilidades y capacidades requeridas para gobernarlas (Katz y Khan, Estados Unidos, 1966). El concepto de sistema como un conjunto de dos o más partes que actúan coherentemente en búsqueda de un objetivo común produjo un fuerte remezón en la concepción que hasta entonces se tenía de administración.

En Teoría y pensamiento administrativo, Ronald Solano (gestiópolis.com, marzo de 2005) plantea, recogiendo las ideas de Katz y Kahan, que al concebir la organización como un todo hay varias implicaciones críticas, entre ellas las siguientes:

- La naturaleza dinámica del ambiente está en conflicto con la tendencia estática de la organización. 
- Está constituida para auto perpetuarse en lugar de cambiar de acuerdo a las transformaciones del ambiente.

- Un sistema organizacional rígido no podrá sobrevivir si no responde adaptándose al entorno.

- Un sistema abierto necesita garantizar la absorción de sus productos por el ambiente.

- Para garantizar su viabilidad, debe ofrecer al ambiente productos por él necesitados o crearle necesidad de tales productos.

- El sistema necesita constante y depurada información del ambiente. Para el sistema es indispensable una retroalimentación constante, depurada y rápida.

El concepto de administración con el transcurrir del tiempo y a partir de tales percepciones iniciales, se enriquece y aparece hoy dotado de componentes que le dan mayor sentido, practicidad y utilidad en la orientación de sistemas organizacionales cada vez más complejos.

Se ha ido saliendo paulatinamente de esos tramos administrativos tan largos y se ha adaptado más a los cambiantes entornos, que exigen rapidez de respuesta a mercados también cambiantes en alto grado y en consecuencia más exigentes, que requieren tramos administrativos rápidos y en consecuencia más cortos.

Se amplía el espectro de los administradores y aparece una concepción gerencial para orientar tales sistemas organizacionales complejos. Se habla de la gestión como el conjunto de factores que permiten planear para hacer, verificar en la medida que se va haciendo y actuar según los resultados obtenidos para fortalecer 0 corregir el rumbo.

La concepción de administradores y gerentes para administrar y dirigir es necesaria pero ya no es suficiente, se requieren gerentes-líderes que tengan capacidades para gestionar los sistemas, entendiendo éstos como un conjunto de partes coherentes que actúan integrada e integralmente para lograr un propósito que es común.

La gestión sistémica tiene entonces que ver directamente con la capacidad de la gerencia para entender la organización como un conjunto de partes, donde el todo es mayor que la suma de esas partes; la intervención de la gerencia es fundamental para orientarla con una visión de conjunto y construir los escenarios para que los procesos y las personas sientan que no son partes aisladas que actúan por su cuenta y riesgo, de manera independiente, sino que, por el contrario, son componentes de un todo al cual, desde su actuación particular en el proceso, aportan enriqueciéndolo, entendiendo que el conjunto tiene un propósito común que es claro y por consiguiente entendible.

Sólo los gerentes profesionales, exitosos en la teoría y práctica del arte de administrar organizaciones, saben que lo importante es orientarse hacia la gerencia de los procesos organizacionales como uno de los pilares de un sistema integral, holístico de planeación y gerencia, esencial para desarrollar la estrategia corporativa ${ }^{20}$.

La Norma NTC ISO 9000/2005, al referirse al tema dentro de un sistema de gestión de la calidad, plantea, respecto al enfoque de sistema para la gestión, que: "identificar, entender y gestionar los procesos interrelacionados como un sistema, contribuye a la eficacia y eficiencia de una organización en el logro de sus objetivos".

Los elementos contenidos en los tres párrafos precedentes se toman como los orientadores, en la categoría de gestión sistémica, para contrastar con la realidad que se encuentra en las organizaciones.

20 Mariño NaVarRete, Hernando. Gerencia de procesos. Bogotá: Alfa Omega, 2002. 


\section{F. Toma de decisiones}

La capacidad de la gerencia para tomar decisiones en un ambiente de incertidumbre, originada por el entorno cambiante y la complejidad de los sistemas organizacionales, ya descrita, es determinante en la permanencia de las organizaciones en el tiempo, alcanzando los resultados que la fortalezcan y le permitan evolucionar a mayor ritmo y mejores condiciones que las demás.

Tomar decisiones entraña siempre la asunción de un riesgo. La forma como toman las decisiones los gerentes, los métodos que utilizan para tomarlas y posteriormente implementarlas en el conjunto organizacional y de mercado es vital para el negocio.

James Stoner en su libro Administración, al recoger la postura de los años 80 del siglo anterior, plantea que la toma de decisiones es parte vital de las actividades de un gerente: "En ese proceso (el de la toma de decisiones) los gerentes deciden asuntos tales como las metas y oportunidades que perseguirán sus empresas, qué recursos se utilizarán y quién realizará las tareas requeridas. El proceso de planeación implica a los gerentes en una serie continua de toma de decisiones, y el acierto con que las tomen desempeña un gran papel para determinar la efectividad de sus planes ${ }^{21}$.

En la teoría administrativa esta mirada se enriquece con elementos que van desde la utilización de la intuición de los gerentes, producto de su experiencia y pálpitos emocionales, hasta la elaboración de complejos modelos matemáticos para eliminar el grado de incertidumbre en la decisión que se toma. La gerencia efectiva debe desarrollar capacidad para que, al tomar la decisión, la exposición al riesgo esté controlada y en consecuencia tenga algún grado de certeza, producto de la claridad en la decisión que se toma.

21 Stoner James, A. F. Administración. México: Prentice Hall, 1988.
La toma de decisión está inmersa dentro de un proceso mediante el cual se determina y elige un camino de acción como solución de una situación o problema particular o general.

Kepner y Tregoe, en el libro El nuevo directivo racional, publicado por la editorial Mc Graw Hill en 1986, recogen el pensamiento de la teoría de toma de decisiones de la década de 1990 y manifiestan que "toda decisión que tomamos nos hace pensar en términos de objetivos, alternativas y riesgos potenciales". Y argumentan que "hacer buenas decisiones depende de tres elementos: la calidad de nuestra definición de los factores específicos que deben ser satisfechos, la calidad de nuestra evaluación de las alternativas disponibles y la calidad de nuestra comprensión de lo que pueden producir esas alternativas (para bien o para mal)".

La toma de decisiones de la gerencia sigue estando enfocada en el análisis de información para buscar mayores niveles de certidumbre en los resultados esperados a partir de las decisiones que eligen.

Patrick Lencioni, en su libro Las cinco tentaciones de un gerente, publicado por la Editorial Norma en 1998, manifiesta su posición frente a la toma de decisiones así:

Muchos gerentes, especialmente los que son excesivamente analíticos, desean asegurarse de que sus decisiones sean correctas, lo cual es imposible en un mundo de incertidumbre en el cual la información es imperfecta. Aún así los ejecutivos que necesitan precisión y lo "correcto" muchas veces postergan sus decisiones y no hacen claridad sobre lo que los demás deben cumplir. Brindan una orientación vaga y vacilante a sus subalternos inmediatos y aspiran a que éstos descubran las respuestas correctas por el camino. Así, es escasa la probabilidad de que los subalternos produzcan los resultados que finalmente los gerentes deciden que quieren.

La evolución de la teoría sobre de decisiones fortalece la necesidad de elegir alternativas, fundamentada tal elección en evidencias que, si bien es cierto que no 
entregan el 100\% de la información requerida, invitan a que el contexto en el cual se toma la decisión sea analizado para tomarla de manera oportuna y de la forma más certera posible.

Las compañías muchas veces toman decisiones basándose en replicar lo que otros hacen, lo que ellos mismos han hecho en el pasado y piensan que funcionó, lo que piensan que por sus cargos deben hacer o lo que consultores les indican. Nada de esto tiene mucho sentido... el ejecutivo debe adoptar el modelo científico de la medicina y aprender a tomar decisiones basándose en la evidencia de los hechos. A través de ir más allá de la sabiduría convencional, las empresas son capaces de triunfar sobre su competencia ${ }^{22}$.

Orienta esta postura a encontrar y analizar de manera técnica información que sustentada en hechos y datos permita a la gerencia elegir vías de acción más expeditas y claras para la comunidad organizacional, estando las decisiones articuladas con la estrategia y los planes superiores del negocio.

El desafío es simplemente basar las decisiones en el mejor y más reciente conocimiento que funcione realmente, tiene sentido pensar que cuando los ejecutivos actúan sobre una lógica mejor y evidencia dura, sus compañías golpeen a la competencia ${ }^{23}$.

Un sistema de gestión de la calidad, exige de la gerencia capacidad para tomar decisiones sustentadas en hechos y datos provenientes del control de información, del análisis técnico de los datos. Todo lo anterior enmarcado dentro de un ambiente de premura y alta competencia.

La NTC ISO 9000/2005 orienta para que la organización, con la gerencia a la cabeza, desarrolle un enfoque basado en hechos y datos para la toma de decisiones y plantea que "las decisiones eficaces se basan en el análisis de los datos y la información".

22 Pfeffer, Jeffrey. Rediseñando la toma de decisiones. En: Harvard Business Review, junio de 2007.

23 Ibid.
Esta categoría -toma de decisiones- recoge la postura de que las decisiones deben estar sustentadas en el análisis de hechos y datos derivados de la consulta y la participación, que no obstante un análisis detenido, permita tomar decisiones oportunas y eficaces en relación con los propósitos superiores de la empresa.

\section{G. Orientación a resultados}

Son los resultados los que mantienen viva una organización. La gerencia, dentro de la visión de conjunto con que debe gestionar el negocio, ha de estar focalizada siempre en que todos los elementos componentes del sistema organizacional al actuar, haciendo uso de recursos, dentro de una planificación claramente establecida para alcanzar propósitos comunes, tiene que producir resultados.

Los resultados son intermedios o finales y dentro de ellos los hay de índole económica y no económica. Una gestión gerencial orientada a resultados debe tener claro, muy claro, cómo logra que el conjunto de los procesos que conforman su sistema, cada uno de ellos, tenga la claridad y consecuente capacidad para alcanzar los resultados que han sido planificados.

Si bien es cierto que los resultados de índole económica son los que sustentan la vida organizacional, no es menos cierto que aquellos de índole no económica son el oxígeno para avanzar en la consecución de los resultados financieros y de índole económica ${ }^{24}$, que finalmente se convierten en los rendimientos y utilidades del negocio.

Es vital que la gerencia tenga totalmente claro este aspecto. Los resultados económicos son el sustento y la vida del negocio, pero no se debe desconocer que otros resultados de índole no económica son los que permiten avanzar de forma más eficiente al tan anhelado resultado económico:

24 Mariño, Hernando. Calidad: lecciones aprendidas. Op. Cit. 
Desde cualquier punto de vista, la función financiera es la base de cualquier negocio. La adecuada organización, funcionamiento y control del sistema financiero de una empresa permitirá conocer a tiempo la situación del negocio y, así mismo, tener y mantener el control y el rumbo de los objetivos programados ${ }^{25}$.

Es indiscutible que los resultados financieros son el alma de las empresas. Lo que se encuentra como un común denominador en la gerencia es que los gerentes se concentran tanto en ellos, con tanta energía, con mentalidad corto - placista extrema, generalmente de manera desordenada, que ese fragor no los deja avanzar en la consecución de tales resultados y en el fortalecimiento del negocio. Se convierte, tal exasperación en un gran obstáculo que no permite ver el fondo.

En consecuencia la implementación de un sistema de gestión de la calidad tiene necesariamente que fortalecer la capacidad de la gerencia para asegurar, de una manera ordenada y metódica, los resultados financieros, los del corto, mediano y por supuesto largo plazo. Pero sin obnubilarse sólo por ello y sin perder la visión de conjunto de la organización que tiene, como sistema, otros sub - sistemas que al actuar articuladamente, con coherencia y congruencia, permiten avanzar por un camino menos incierto, con el orden requerido en la consecución de los resultados de índole económica.

Implementar un sistema de gestión de la calidad "también tiene que ver con el desarrollo de una infraestructura que genere indicadores sobre su desempeño y el valor agregado en los resultados del negocio. Aquí se podría plantear la siguiente condición: los resultados financieros de una empresa no son otra cosa que el reflejo o el producto de su sistema de gestión de la calidad"26.

25 Perdomo Burgos, Álvaro. Gestión de la calidad en los procesos financieros. Bogotá: ICONTEC, División de publicaciones, marzo de 2002.

26 Ibid.
La generación de valor que debe producirse al encauzar el sistema en esa vía y con tal filosofía, es un resultado más que la gestión del negocio debe producir. Tal generación de valor ha de alcanzar a todas las partes interesadas, privilegiadamente los clientes, que son los que hacen posible la existencia de las organizaciones.

Un sistema de gestión de la calidad, luego de implementado, debe producir un efecto positivo en esta orientación a resultados, tanto económicos como de índole no económica, y en la capacidad de gestión de la gerencia para hacerlo cada vez más real y, en consecuencia, contar con un sistema más eficiente y eficaz.

Esta categoría de orientación a resultados se toma como la capacidad que la gerencia tiene para orientar la gestión hacia el logro de resultados mediante la determinación eficaz, precisa de horizontes económicos y no económicos, para que los trabajadores puedan articular sus actividades con tales resultados.

\section{H. Gestión del talento humano}

La gestión del talento humano como categoría para la investigación se toma como el sistema que garantiza la determinación y el conocimiento de las competencias del personal antes de su ingreso, así como la mejora de competencias de las personas que están en la organización, gestión que reconoce el talento de las personas como factor fundamental para alcanzar los objetivos planificados por la organización.

Las competencias de los seres humanos tienen que ver con la capacidad que demuestran para lograr resultados de éxito en un contexto laboral determinado.

Las competencias, están directamente relacionadas con el talento de los seres humanos, que tiene relación directa con el saber y la habilidad para hacer.

Se trata de aunar dos capacidades, la intelectual que está materializada en el saber, y la habilidad para hacer. El saber 
y el saber hacer viajan juntos cuando nos referimos al talento. El uno sin el otro no tienen valor. El saber, si no se aplica, no aporta más que la satisfacción intelectual de algunos, y el saber hacer sin saber, no tiene futuro. El saber es el sustrato que permite mejorar, avanzar en el saber hacer y dar sentido a los problemas. El saber nos ayuda a decidir y el saber hacer nos ayuda a resolver. El talento supera al conocimiento. El talento añade sobre el conocimiento el concepto de ejecución, la actividad ejecutora y creadora ${ }^{27}$.

La gestión del talento humano se enfoca a generar y dinamizar las actividades suficientes encaminadas a determinar las competencias requeridas en el negocio para alcanzar los aspectos crucialmente importantes que emanan de su visión, misión, políicas, objetivos, es decir, de todo su direccionamiento estratégico, para el cual un sistema de gestión de la calidad se convierte en un eslabón crítico.

La gerencia es la responsable de producir los escenarios adecuados al interior de la organización para asegurar que el proceso de gestión del talento humano se oriente en tal sentido y busque a través de prácticas de gestión adecuadas que "las personas y las empresas alcancen su máximo nivel de eficacia; que las estrategias empresariales no sean meros ideales, si no que se conviertan en acciones" 28 .

En consecuencia, los seres humanos en las empresas deben ser concebidos como los que posibilitan, a través de sus conocimientos y el desarrollo de competencias pertinentes al negocio, el logro de los resultados planificados, haciendo realidad los objetivos presupuestados. Desde este enfoque los seres humanos son mucho más que recursos.

27 GoÑi, Juan José; Vea, Ricardo. Gestión avanzada del talento. En: Training \& Development Digest, marzo de 2002.

28 Ulrich, Dave. ¿Qué es lo próximo que va a pasar en el mundo de los Recursos Humanos? En: Training \& Development Digest, marzo de 2002.
La gerencia de las empresas debe salir ya del estrecho marco de considerar a las personas como un recurso más del proceso productivo. Es cierto que en términos cuánticos y de costos son eso: recursos que hacen posible que un proceso se logre o no se logre, que un resultado se alcance 0 no se alcance. Que el estado de pérdidas y ganancias, mejor llamado de ingresos y resultados, refleja como un costo más.

Ese paradigma, de considerar las personas como simples recursos que se quitan y se ponen, se interpone cada vez con mayor fuerza en el camino de alcanzar con eficiencia y eficacia los resultados que la gerencia planea. Persiste allí una fuerte contradicción.

Si la noción y filosofía imperante al interior de los sistemas empresariales, es la de que las personas son recursos, la gente aprende a actuar y a comportarse como simple recurso. No se compromete, nunca van a asumir la responsabilidad que la gerencia equivocadamente espera.

Yo sostengo, a partir de experiencias acumuladas en mi ya larga trayectoria empresarial y de consultoría en diferentes sectores industriales y económicos, que las personas no son recursos, muy al contrario, son generadores de recursos, que con su capacidad e interés hacen posible que las actividades se enriquezcan a partir de su participación y compromiso y facilitan el logro de los objetivos que con claridad se construyen también con su participación.

Por supuesto que tal renovación en este paradigma exige avanzar en un nuevo modelo mental en la gerencia de las empresas y esto demanda dedicación, esfuerzo y vocación de construcción. Tener una mirada menos viciada por la angustia que transmite el estar concentrados en el corto plazo.

Se debe ampliar el espectro de la gestión para reconocer que se ha estado concentrado en realizar acti- 
vidades operativas en materia de personal, que tocan primariamente con los temas legales que pueden ocasionar sanciones o líos de orden judicial o con los entes de control. No se desconoce que estos aspectos son importantes, pero no son suficientes para producir diferenciación en el mercado, como seguramente lo pide la estrategia de la empresa.

El esfuerzo de la gerencia debe orientarse a nutrir el sistema organizacional con gente talentosa, que tenga potencial de aprendizaje y que, al enfocar sus talentos y competencias en lo que la empresa concibe y comunica como lo crucialmente importante, sume valor y potencialice el sistema para avanzar por el rumbo determinado en el direccionamiento estratégico del negocio. No obstante la creciente tercerización, apoyo en servicios temporales o en cooperativas de trabajo asociado.

La forma, los métodos y la disposición de la gerencia para determinar cuáles son las competencias que requiere su negocio, cómo las evidencia y cómo las mantiene, fortalece y hace surgir nuevas capacidades a partir de la dinámica propia del sistema organizacional y su entorno, son determinantes en una más eficaz gestión del talento humano. De tales aspectos se ocupa la gestión del talento humano.

El sistema de gestión de la calidad, al reclamar la participación del personal como principio, plantea que "el personal, a todos los niveles, es la esencia de una organización y su total compromiso posibilita que sus habilidades sean usadas para beneficio de la organización" (Norma NTC ISO 9000/2005, numeral 0.2 literal c).

En consecuencia, el efecto que debe producir la implementación de un sistema de gestión de la calidad en la capacidad de conducción de las organizaciones relacionada con la gestión del talento humano tiene que ser positivo y de alto impacto.

\section{Mejora continua}

Esta categoría de la investigación se toma como la capacidad que desarrolla la gerencia para buscar intencionalmente, recurrentemente y de forma incesante maneras de hacer mejor el trabajo, a través de metodologías claramente establecidas que permiten mejorar el cumplimiento de estándares, procedimientos o protocolos establecidos, para el proceso o producto.

Uno de los pilares de la filosofía gerencial de la calidad total es el mejoramiento. En tal contexto, mejoramiento significa buscar métodos y maneras de realizar de forma más adecuada el trabajo. Todo trabajo es un proceso y elevar la capacidad para entregar mejores bienes y servicios a nuestros clientes con el fin de satisfacer sus necesidades y expectativas, 0 aún mejor, superarlas y fascinarlos. Lograr mejoramiento es muy distinto a controlar el proceso, manteniendo el stato quo, pues a través del mejoramiento logramos resultados nunca obtenidos, mucho mejores que los actuales, pero no como fruto del azar o la buena suerte, sino como un logro planeado ${ }^{29}$.

Mejorar significa salir de un estado no deseado en que se encuentra un sistema para alcanzar un nivel esperado de respuesta. Ahora bien, esa mejora ha de lograrse de manera continua y sostenida en el tiempo, como producto de un sistema orientado a desarrollar capacidad en los miembros de la organización, encabezados por la gerencia, para producir análisis y decisiones adecuadas que permitan enfrentar los problemas, evitando su recurrencia.

El estado actual de la economía, de los mercados a nivel mundial, impactados por una galopante globalización -con todas sus asimetrías-, no permite, no acepta que las organizaciones persistan en la improvisación y, a partir de ella, en concentrar si no todos, la mayoría de sus esfuerzos en administrar problemas que nunca se terminan de solucionar. Lo que se llama en lenguaje

29 MARIÑO NAVARRETE, Hernando, Gerencia de Procesos. Editorial Alfaomega. Bogotá 2002. 
coloquial, administraciones "bomberiles", que tratan de apagar los incendios sin conseguirlo.

Por consiguiente la gerencia debe, como uno de los elementos fundamentales de su actuar, gestionar el sistema organizacional para producir un salto cuántico en la capacidad para resolver de forma eficaz las distorsiones que presenta el sistema de la empresa.

Producto de las investigaciones y del enriquecimiento de la visión sistémica, ya mencionada, se encontró que los sistemas siempre tienden al desorden, producen una alta tendencia a la entropía. Una adecuada gestión de la gerencia debe reconocer estos estados y trabajar metódicamente para encauzar el sistema organizacional por los caminos diseñados, mediante la aplicación de herramientas que lo hagan posible.

La norma NTC ISO 9004/2000, en su numeral 8.5.1, manifiesta que "la dirección debería buscar continuamente la eficacia y la eficiencia de los procesos de la organización, más que esperar que un problema revele oportunidades para la mejora". Y continúa en el numeral 8.5.4 diciendo: "Para ayudar en el aseguramiento del futuro de la organización y la satisfacción de las partes interesadas, la dirección debería crear una cultura que involucre a las personas de manera activa en la búsqueda de oportunidades de mejora en el desempeño de los procesos, las actividades y productos".

A su vez, la norma NTC ISO 9001/2000 plantea, en su numeral 8.5.1, que "la organización debe mejorar continuamente la eficacia del sistema de gestión de la calidad mediante el uso de la política de calidad, los objetivos de la calidad, los resultados de las auditorías internas, el análisis de datos, las acciones correctivas y preventivas y la revisión por la dirección”.

Tiene pues, la gerencia, orientaciones precisas para anticipar y resolver problemas, así como para posibilitar nuevos proyectos que metódicamente conduzcan al sistema por los senderos determinados en su rumbo estratégico, para dar solución a los problemas a través de un análisis de causas que permita descubrir su raíz y trabajar en su eliminación mediante acciones correctivas, y en la anticipación a potenciales problemas con la aplicación de metódicas acciones preventivas y el desarrollo de mayores capacidades mediante acciones de mejora.

\section{RESULTADOS}

A continuación se presentan los resultados obtenidos en la investigación a partir del análisis de cada categoría, el cual se hace con la información derivada de las entrevistas con los gerentes y de las encuestas aplicadas a los niveles tácticos, técnicos y operativos de las organizaciones, como ya quedó expuesto en la presentación de la investigación.

\section{A. Planeación estratégica}

No obstante que las empresas participantes cuentan con una misión y visión, analizada la información recopilada en la entrevista con los gerentes sobre el tema de la planeación y la estrategia para llevarla a cabo se puede concluir que no se está haciendo una planeación estratégica formal.

Esta respuesta ante la pregunta de los planes estratégicos y qué se está haciendo en esta materia evidencia desconocimiento del asunto. Posteriormente este gerente manifiesta que no cree en los planes estratégicos porque son muy enredados.

El gerente 2 evidencia que no hay una planeación estratégica, aunque supone que los derroteros de la organización son claros, producir y vender bien. "Eso es lo que piden los socios, rentabilidad, y él tiene que ver cómo la logra".

En lo referido anteriormente se evidencia que el concepto de planeación estratégica no está muy compene- 
trado en la gerencia y en consecuencia la aproximación a visualizarla como una herramienta útil y práctica es aún distante y genera cierto escepticismo, no obstante que tienen conciencia que para el sistema de gestión de la calidad es un factor importante.

No aparecen con claridad, en estas consideraciones, una postura técnica de la gerencia sobre el tema de la planeación y de la estrategia organizacional. No se evidencia frente al tema una postura metódica que permita establecer que el tema se está tratando con el rigor necesario para que produzca efectos importantes en las organizaciones.

Sólo el gerente 1 traza grandes pinceladas desde su particular punto de vista, trabajando sólo, de cómo podría llegar a un plan de trabajo que en su concepto puede ser el conveniente para la organización.

Ahora bien, no se pretende que las organizaciones muestren unos esquemas rígidos de planeación tradicional, como se dijo en el marco conceptual, donde es entendible que planear para el largo plazo (como ha sido usual según los modelos conocidos) en nuestro medio, donde las externalidades resienten mucho más el comportamiento y los planes de las empresas, de la misma forma en que puede hacerse en otras economías más estables, no es tan fácil y no resulta muchas veces recomendable, pero se espera que la gerencia trabaje en estos aspectos de manera metódica, revisando lo que significa para cada una de ellas, el corto, mediano y largo plazo, de tal forma que puedan realizarse planes ordenados y consecuentes con el estudio y concepción de la organización sobre el mercado y el entorno en el cual se desenvuelven y proyectan sus negocios.

Los gerentes saben que tienen unos propósitos por alcanzar, que tienen unos resultados por lograr, pero no existe, como se vio, un método claramente establecido que permita a la organización contar con un plan que articule los esfuerzos del conjunto organizacional hacia un objetivo u objetivos comunes.

No se realiza un trabajo intencional para construir un plan enfocado en el mercado que ayude a darle a la empresa una ventaja competitiva sobre sus competidores a través de la diferenciación.

No se evidenció que exista en los gerentes un patrón de decisiones alrededor de los aspectos crucialmente importantes para el negocio, que intencionalmente establezcan la dirección de la organización a mediano y largo plazo y determinen su destino.

En los casos analizados, se hacen esfuerzos por dotarse de algún norte para el negocio, que está jalonado de manera imperante por vender su producto o servicio. "Se debe vender y vender bien", es la premisa y la preocupación central en todos los casos, pero no tienen una forma o manera técnicamente establecida, que sea metódica y dé origen a un conjunto de información bien estructurada, para que se convierta en una planeación estratégica, con planes tácticos y operativos que permitan llevarlos a cabo de manera controlada y puedan saber si en realidad están vendiendo y vendiendo bien.

Ese esfuerzo está centrado en el corto plazo, las energías y concentración de las personas se dedican a lograr los resultados del día a día en una gran proporción.

Los esfuerzos que se realizan en la empresas son dispersos; van desde el trabajo sólo del gerente, con un nivel mínimo de consulta, que parte del supuesto de que los derroteros para el negocio están claramente trazados y que la gente los debe saber, pasando por el que realiza algún nivel de análisis de información y consulta que produce acuerdos alrededor de aspectos que impactan la vida institucional y la prestación del servicio. Manejan un grado básico de información que 
generalmente está ligada con lo que ha ocurrido en ciclos anteriores para sustentar determinados propósitos y proyectos de trabajo futuros.

Manifiestan que el sistema de gestión de la calidad les ha abierto mayores posibilidades para acercarse al tema, en la medida en que les ha permitido organizarse mejor y visualizar el negocio de una manera un poco más ordenada, pero es evidente que la implementación del sistema no ha logrado todavía producir el impacto requerido para trabajar con juicio en la determinación adecuada de un derrotero, metódica y técnicamente construido, que les sirva de eje vertebrador para priorizar e impulsar los proyectos de trabajo, la distribución y asignación de recursos, la apropiación de competencias necesarias para la organización, en fin, que permita a la empresa organizar su estructura y modelo de negocio de tal forma que se convierta en un propósito para el cual todos deben trabajar, y que puedan controlar su avance y estar atentos a revisar cuando sea necesario.

No tienen claro cómo el sistema de gestión de la calidad se articula con los esbozos de planes desarrollados de la manera anteriormente expuesta, cuando existe algún asomo, ni el alcance que éste debe tener para construir mayor capacidad en la conducción, orientación y gobierno de la organización.

Se pudo evidenciar que en este factor los gerentes han encontrado, a partir del sistema de gestión de la calidad, sustento para ordenar la operación de la empresa, pero continúan moviéndose sustancialmente en el campo operativo, en el corto plazo, sin avanzar en delinear una propuesta ordenada de trabajo para el negocio, de mayor alcance y horizonte concreto.

Las organizaciones han definido su misión - visión sin participación de los trabajadores. Alguien la hizo: el fundador, el gerente o un consultor se las ayudó a depurar. No se encontraron valores o principios establecidos. Como se comentó anteriormente, los objetivos transmitidos están orientados al corto plazo y ligados estrechamente con la operación del cargo y, en el mejor de los casos, con los del área y no tanto con los del proceso. No se evidenció que los gerentes visualicen 0 hayan trabajado en este factor como herramienta que posibilita ver la organización como un todo y desde allí priorizar el trabajo de procesos y definir los objetivos de cargos y oficios de manera alineada.

En consecuencia y teniendo en cuenta las categorías establecidas -ya analizadas- el sistema de gestión de la calidad no ha producido efecto visible sobre las habilidades y capacidad en la gerencia para abocar el tema de planeación y estrategia para las organizaciones de manera metódica y sistémica, de tal forma que apoye la gestión de la gerencia disminuyendo la incertidumbre y la exposición al riesgo en los mercados que atienden.

Del análisis de las encuestas a los trabajadores de niveles diferentes a los de la gerencia se puede concluir que perciben favorablemente que la empresa tiene un derrotero que se les ha presentado como una misión o visión, pero su percepción disminuye cuando se plantea la manera en que ellos participan y la forma en que la empresa se asegura de que los planes o programas que se deben realizar sean claros para ellos; la percepción positiva que tienen es impactada hacia la disminución por la forma en que la organización les informa sobre los objetivos que se deben alcanzar en el trabajo de cada uno, en articulación con los propósitos del negocio.

\section{B. Comunicación}

En este factor se pudo evidenciar que las organizaciones realizan esfuerzos por tener algunos mecanismos que les permitan informar a las personas sobre los aspectos que son fundamentales para el cumplimiento de su trabajo. Órdenes de trabajo, instrucciones de trabajo ligadas directamente con información para hacer 0 
no hacer, circunscritas fundamentalmente a la cotidianidad de las actividades empresariales.

Es evidente que los gerentes se apoyan para desplegar esta información en reuniones de trabajo o comités de calidad, en las cuales se analizan los aspectos relacionados con el quehacer puntual de la operación y del sistema, para tomar decisiones que son informadas directamente o por parte de los responsables a quienes deben aplicar las decisiones e instrucciones particulares en el día a día de las actividades y en consecuencia en el corto plazo.

Es apreciable que el sistema de gestión de la calidad ha comenzado a desarrollar un mayor grado de conciencia en los gerentes sobre la importancia de entregar información a la comunidad organizacional. Pero por igual, es claramente evidente que siguen circunscritos en el corto plazo de las órdenes y contraórdenes, mejorando para el efecto el mecanismo de las reuniones o comités.

Es evidente que la gerencia, en este tema, se está quedando en la información. No existe un sistema para comunicar que de manera metódica busque como un proceso, comunicación pertinente que permita un buen nivel de entendimiento y comprensión de los horizontes del negocio, así, como de las responsabilidades y quehaceres en cada uno de los procesos, cargos y oficios de la empresa.

No es posible que los trabajadores de las organizaciones pasen a ser actores en sus propias responsabilidades, si no comprenden con claridad cómo se articula su trabajo con los propósitos fundamentales de la organización y del sistema determinado por ella para alcanzar los resultados, de acuerdo al marco conceptual de la categoría en análisis. Es concluyente de lo expuesto por lo gerentes, que no es esa la intencionalidad con la cual "comunican".
La gerencia se ha quedado únicamente en informar, pues en ningún caso se pudo establecer que se valide el nivel o grado de entendimiento de las personas que reciben la información, para garantizar lo que el sistema requiere para actuar correctamente y según lo planificado por la gerencia.

Es más, las organizaciones son redes permanentes de comunicación, que demandan un sistema metódico para asegurar que se da en todos los niveles y en los diferentes procesos en doble vía, validando que lo comunicado es entendido por quienes tienen que actuar a partir de la comunicación, por quienes tienen que realizar las operaciones y actividades necesarias, obteniendo resultados o rindiendo cuentas sobre lo actuado para asegurar la eficacia de las mismas y la eficiencia de los procesos. Es evidente que los gerentes no trabajan con tal nivel de profundidad en los procesos de comunicación. Puede decirse que se está cumpliendo con lo mínimo de lo mínimo en materia de comunicación.

La concepción aplicada que se encontró en los gerentes, es que la comunicación es de una sola vía; de ahí que haya utilizado más el término "información". Eso es lo que se está haciendo: informando sobre aspectos puntuales y particulares, como se dijo anteriormente. En este contexto, no se asegura y se valida que la información se despliegue a los niveles pertinentes, precisamente porque no se cuenta con un sistema de comunicación.

Los trabajadores tienen una percepción favorable en materia de comunicación. Esto, puede deberse a los mecanismos que las empresas han fortalecido para informar sobre aspectos puntuales y órdenes de trabajo.

La favorabilidad en tal percepción disminuye cuando se indaga por temas más allá del diario quehacer; desempeño de la organización en el mercado, es de- 
cir, cómo nos está yendo a todos en este negocio; en lo oportuno de la información que es importante para el trabajo de ellos y el conocimiento de lo derroteros de la empresa.

En materia de comunicación, el sistema de gestión de la calidad no ha logrado producir un efecto importante en las habilidades de los gerentes para orientar verdaderos procesos de comunicación que faciliten un adecuado grado de alineamiento de los propósitos de la organización con el quehacer y las responsabilidades de los cargos y viceversa, que sirva de soporte sustancial para asegurar la eficacia de la gestión de la gerencia en el negocio.

\section{Organización orientada al cliente}

La orientación hacia el cliente los gerentes la conciben como el establecimiento de mecanismos que permitan tener canales de comunicación para recoger sus requisitos y necesidades, inquietudes y sugerencias, quejas, reclamos, devoluciones, así como encuestas que les deje validar el grado de satisfacción por el cumplimiento de los compromisos asumidos por la empresa relacionados con sus productos y servicios. Este es un primer avance en el sentido correcto.

Se aprecia el esfuerzo por enfocar la organización más hacia el cliente, pero no se avanza más allá de cumplir con unos requisitos básicos desde el punto de vista operativo. Los planteamientos hechos por los gerentes recogen orientaciones puntuales sobre la satisfacción del cliente y algunos mecanismos que las gerencias vienen utilizando.

No es suficientemente claro para la gerencia que este factor debe tener un mayor alcance en la gestión del negocio y en consecuencia va más allá de las encuestas de satisfacción y de mecanismos que permitan responder a quejas, reclamos y sugerencias. Que la habilidad de la gerencia se debe orientar a desarrollar toda una vocación para que la organización como un conjunto, en todos sus procesos y niveles, no sólo en unos pocos, se oriente permanentemente hacia el cliente.

En ese sentido, la gestión de las organizaciones no entrega señales vigorosas de estar avanzando de una manera sistémica ni sistemática para lograr este enfoque, que en cambio si es una exigencia cada vez más apremiante por parte de los consumidores y del mercado en general.

Los gerentes no ignoran del todo que deben incrementar la capacidad de la organización para alcanzar altos grados de contacto real con el mercado: cómo se comporta, tendencias, evolución y enfocarse hacia el cliente, pero no han descubierto el camino que conduce hacia ese horizonte, no obstante que el sistema de gestión de la calidad, se lo plantea y lo invita a mejorar, a ampliar el espectro de entendimiento y aplicación consecuente de vocación de toda la organización hacia el cliente.

Es el cliente el que fija la calidad. No existe frontera entre producto y servicio. El cliente busca cada vez más, mayor valor agregado en los servicios que recibe. Es un mercado de demandantes con mayores exigencias y posibilidades de encontrar otros proveedores, así como productos y servicios sustitutos. La gerencia conoce que hacia allá sigue avanzando el mercado, pero no ha desarrollado conciencia suficiente para progresar en ese sentido.

Lo que se trasmite por parte de las gerencias está encaminado básicamente a cumplir con los requisitos mínimos que exige la norma y no tener complicaciones en las auditorías del organismo certificador.

Se evidencia que son aspectos puntuales que están desarticulados, huérfanos de una estrategia poderosa que les permita trabajar como un solo cuerpo organizacional en la orientación hacia el cliente. En conse- 
cuencia, no hay manifestaciones explíitas como vocación de la empresa de mantenerse permanentemente orientada hacia el cliente.

La concepción del cliente es sólo externa. Los gerentes no ven a sus trabajadores con la óptica de clientes internos. Desde luego que el cliente por el cual se debe trabajar con todas las energías es por quien demanda y consume productos y servicios; aunque es sabido que aplicar la filosofía de clientes a los trabajadores ayuda bastante a desarrollar conciencia organizacional para fortalecer la orientación y vocación hacia el cliente externo.

Se evidenció que la filosofía de enfocarse al cliente proviene más del afán por evitarse problemas al interior de la organización en la producción o prestación del servicio. Se debe trabajar en mantener al cliente satisfecho, para que no haya quejas o reclamos, devoluciones y, si las hay, "a ver cómo le hacemos el favor".

Por el contrario, no es evidente que la gerencia trabaje en este tema con la mentalidad de conocer mejor su mercado y sus clientes con la finalidad de incrementar la capacidad de gestión, las competencias de la organización para actuar como un verdadero sistema en pos de la satisfacción de los requisitos y necesidades del cliente, de sus expectativas, de convertirse en una opción de solución de sus necesidades y producir su fascinación y conseguir que mediante esa vía se incremente el portafolio de clientes.

Los gerentes aducen que esto es costoso y hasta utópico y más grave aún, peligroso para el negocio.

Los gerentes siguen considerando el foco primordial de toda su gestión el interior de la organización. Manifiestan que el cliente lo es, pero actúan con prioridades internas para satisfacer requisitos también internos de procedimientos, protocolos que de alguna manera esperan los conduzca, como ya se dijo, a no tener inconvenientes con el cliente. Lo cual como se explicó, invierte el orden de las ideas en este tema.

En consecuencia, las organizaciones se encuentran inmersas en una espiral estática en su posición y no se reflejan saltos cuánticos, ascendentes, en la gestión, como debiera ser.

Los trabajadores tienen una percepción medianamente favorable sobre cómo la organización enfoca sus actividades hacia el cliente y en la forma en que la empresa aplica acciones correctivas para solucionar problemas en ese enfoque.

Tal percepción es menos favorable y en consecuencia tiende a la baja cuando se indaga por la forma en que los procesos trabajan con un enfoque hacia el cliente y la participación que ellos tienen para apoyar y mejorar este enfoque, y es menos favorable aún al averiguar sobre los ajustes necesarios que aplican en sus procesos para que las necesidades de los clientes estén ampliamente satisfechas, lo que permite afirmar, como ya se dijo, que la prioridad del trabajo es para satisfacer requisitos internos, que no son tan claros, para ellos, ante los clientes.

En esta categoría el sistema de gestión de la calidad ha surtido a la administración de mecanismos y herramientas para favorecer la disminución de problemas con el cliente y medir su grado de satisfacción, pero no ha logrado impactar las habilidades y capacidades de los gerentes para producir una gestión que tenga su eje de actividad nuclear en el mercado, en el cliente, sin, desde luego, desatender los aspectos internos que son crucialmente importantes para generar una organización que, como un todo, se oriente y asuma la filosofía en la cual el cliente es el primordial y verdadero foco de toda la actividad organizacional. 


\section{Liderazgo}

Es claro que los gerentes siguen trabajando más en la administración de las personas que en el desarrollo de liderazgos organizacionales.

Los estilos de dirección van desde la autocracia, hasta algún grado primario de participación, pasando por el de dejar hacer dejar pasar, característico de la fisiocracia, que se confunde con empoderamiento, sin un nivel claro de conducción.

No se evidenció que los gerentes trabajen en el conocimiento de la cultura de las empresas; en el talento que pueden tener sus trabajadores y el requerido para asegurar el fortalecimiento del negocio. Este asunto incide en gran medida en la generación de un clima adecuado para que los trabajadores puedan encontrar pasión de la cual alimentarse y crear confianza para el avance de sus actividades.

Los gerentes saben que requieren gente que pueda desempeñar sus obligaciones y responsabilidades con mayores capacidades, pero no si esas personas son las adecuadas para fortalecer la capacidad de gestión del sistema frente a los continuos cambios en tecnología y exigencias del mercado. No son precisos, tampoco, en los métodos para asegurar que las personas que se vinculan a la organización cuentan con las potencialidades necesarias para enriquecer el medio de trabajo en el cual deben desenvolverse. Se fijan sí, en las capacidades técnicas para el desempeño de la labor, de la tarea, del cargo, de la función.

Los gerentes también saben que no lo pueden hacer todo solos, que requieren de personas que los apoyen en el análisis de información y aún en la toma de decisiones, pero manifiestan que cuando tratan de hacerlo no encuentran personas que con buen nivel de capacidad den soporte a la gerencia y en consecuencia terminan asumiendo, en la mayoría de los casos, labo- res que no les corresponden. Es un círculo vicioso que no se rompe y la gerencia se muestra poco decidida a romperlo.

Y es que es bastante lógico, no cuentan con personal con las capacidades suficientes, pero tampoco trabajan en planes que les permitan crear un escenario organizacional propicio para que los trabajadores sientan y reconozcan que deben participar más y en consecuencia escalar el nivel de responsabilidad dentro de su proceso, alineados con los objetivos de la empresa, asumiendo actitudes de liderazgo en sus procesos y responsabilidades. Este aspecto es concluyente en las respuestas encontradas.

Por esta razón, el tan anhelado compromiso no aparece, amén de los estilos gerenciales de conducir a los trabajadores, que han aprendido, a partir de ellos, a recibir órdenes y actuar con total apego a ellas, para de esta manera minimizar el riesgo que puedan correr, que pueda poner en peligro sus trabajos y la zona de comodidad en la cual se han acostumbrado a moverse.

La gerencia no ha desarrollado las habilidades y capacidades requeridas para trabajar con coherencia y propósito específicos en estilos de gobierno que permitan el enriquecimiento de la cultura para que los trabajadores manifiesten el grado suficiente de compromiso, dejando a un lado los temores que los atan, y que en consecuencia los sistemas de trabajo se vean fortalecidos con el aporte de todas las partes interesadas. Es decir, no hay vocación explícita de liderazgo en la gerencia, existe, como ya se dijo, administración de actividades que buscan minimizar el grado de problemas, manteniendo en orden la casa, de manera que las tareas mandadas se hagan.

Este aspecto, por supuesto, es un obstáculo mayúsculo para que los sistemas de gestión de la calidad crezcan y avancen con mayor utilidad. Si no se cuenta con un estilo de gobierno en el cual vean claramente que su 
participación y nivel de compromiso es vital y que la organización en cabeza de la gerencia trabaja para ello, haciéndolo evidente mediante buena comunicación, acción y planes concretos, va a ser bastante intrincado que los sistemas arrojen resultados de alto impacto.

Los trabajadores tienen una percepción de conformidad con los estilos de conducción de la gerencia y es favorable su mirada sobre el tema, aunque dentro de las categorías analizadas es una de las más bajas, con altibajos entre empresas y al interior de las mismas.

La percepción menos favorable se da cuando se afirma que el estilo de los directivos se caracteriza por una actitud que promueve las iniciativas de sus empleados, siguiéndola en la percepción más desfavorable la enunciación de: el estilo de los directivos se caracteriza por una actitud orientadora hacia el trabajo en equipo. Esto permite concluir que la gerencia no está actuando con sentido de liderazgo para producir un efecto claro sobre el compromiso de quienes trabajan para el negocio.

\section{E. Gestión sistémica}

Es perceptible que la gerencia en este punto viene haciendo esfuerzos por lograr una organización que esté más orientada hacia el reconocimiento de objetivos que produzcan un mayor grado de unidad, pero lo viene haciendo sin orden, en forma reactiva, a partir de los problemas del día a día, y no proactiva, sobre iniciativas de organización - mercado que permitan construir intencionalmente visión sistémica. Se evidencia que hay buenas intenciones de crear una visión conjunta, pero se deduce a partir de la información y vivencias suministradas que no es claro lo que se debe aplicar para lograrlo. Buscan generar esa mirada de conjunto a través de reuniones, de comités de calidad formales 0 de reuniones de trabajo.

Se puede apreciar que los gerentes hacen esfuerzos por darle un poco más de articulación a las actividades del servicio o de la producción a partir de la implementación de un sistema de gestión de la calidad, pero en el lenguaje y la definición gerencial, siguen estando presente más las partes que el todo.

El concepto de gestión y la visión de sistema como factores que permiten conjugar de manera estructurada y técnica el horizonte de la empresa, para que los trabajadores lo reconozcan, interpreten, vivencien y logre constituirse en eje articulador de su trabajo y de la interacción con el de los demás, no aflora dentro del modelo mental con el cual los gerentes pretenden direccionar sus empresas.

Esa gestión sistémica tiene que ver directamente con la capacidad de la gerencia para entender la organización como un conjunto de partes, donde el todo es mayor que la suma de esas partes y su intervención, la de la gerencia, es fundamental para orientarla con una visión de conjunto y construir los escenarios para que los procesos y las personas sientan que no son partes aisladas que actúan por su cuenta y riesgo, de manera independiente, sino, por el contrario, componentes de un todo.

$\mathrm{Al}$ referirse a esta categoría, los gerentes se quedan en el escenario de los objetivos de trabajo particular de cada cargo, de sus indicadores, que impactan los resultados en el corto plazo, sin avanzar con orden ni de forma metódica a los de proceso, ni a la interacción de los procesos dentro del sistema de gestión de la calidad.

Se manifiesta, por parte de la gerencia, en ciertos casos, que el sistema ha logrado producir algún efecto de mayor conjunto en las personas alrededor básicamente de objetivos en la producción, comercialización o prestación del servicio, pero aislados de otros procesos que direccionan o apoyan las labores, siendo extremadamente débil la manera como se concibe que el trabajo desde los procesos impacta el futuro de la organización y de la orientación hacia el cliente y el mercado. 
No es clara la forma en que ellos, los gerentes, deben cimentar las bases y construir la visión de sistema en la empresa, de tal manera que puedan orientar su quehacer gerencial hacia una poderosa gestión sistémica que reconozca intencionalmente sus elementos componentes, prácticos y útiles, que fortalezcan el gobierno de la organización y permitan la concentración de energías alrededor de los propósitos fundamentales y los aspectos cruciales del negocio, y que lo hagan articuladamente, en el corto, mediano y largo plazo, tal como se analizó en la presentación de las categorías.

Para el investigador es evidente, a luz de los análisis realizados, que la gerencia sigue trabajando en el corto plazo, concentrada en la parte operativa del negocio; en los resultados del día a día. Enfocada en la producción y la venta o prestación del servicio, y eso no es malo, lo que ocurre es que ya no es suficiente para competir en un mercado cada vez más abierto, volátil y por consiguiente con cambios inesperados que someten a las organizaciones a un alto nivel de incertidumbre y de riesgos mayores para su rentabilidad, supervivencia y crecimiento.

Este modelo mental para direccionar deja a la empresa amarrada, muy ligada a los vaivenes del corto plazo y de la problemática operativa -asuntos que requieren atención y cuidado- desligada de una visión de conjunto, de sistema, que pueda sustentar nuevos resultados por lo menos en el mediano plazo y le permita a la empresa, sin tantos traumatismos y costosos desgastes, responder como un todo, adaptarse como un sistema a la volatilidad de un mercado más competido y de una economía altamente fluctuante.

El sistema de gestión de la calidad, en esta categoría, no ha producido un efecto en las habilidades y capacidad de la gerencia, para orientar la organización, para gestionarla como un sistema. Sigue imperando en el modelo mental de los gerentes una visión mecanicista de la organización, más hacia las partes, que hacia el todo y, desde allí, desde esa mirada mecanicista, se pretende construir la sensación de conjunto. Forma de enfocarlo, que sin duda resulta bastante difícil y costosa.

Los trabajadores tienen una percepción medianamente favorable sobre la gestión sistémica en la organización, percepción que es menos favorable cuando se indaga por si la gerencia ha establecido planes operativos comunes a todas las áreas, además de los planes operativos específicos de cada proceso, asunto que afirma la percepción mecanicista que existe en la gerencia para la orientación de la empresa. Igualmente la percepción no es tan favorable, calificada más bajo, cuando se plantea si la gerencia tiene en cuenta la labor de otros procesos relacionados con el mío para facilitar la consecución de resultados comunes.

Ellos, los trabajadores, se ven trabajando más en las partes específicas de su trabajo y no en el conjunto de los procesos y de cómo su trabajo impacta los resultados frente al cliente y al mercado.

\section{F. Toma de decisiones}

Los gerentes conciben la toma de decisiones como un factor de alta criticidad y complejidad. Se evidenció que en las empresas se consulta con los niveles inmediatos a la gerencia y en algunos casos con los niveles operativos las decisiones que se deben tomar en el día a día operacional. Manifiestan que tienen órganos consultivos: reuniones, comités académicos, comités de calidad, reuniones particulares según la problemática, mediante los cuales pulsan el concepto de las personas y en algunos casos de los procesos.

También es evidente que tratándose de decisiones de mayor impacto para la empresa el nivel de consulta no aparece y manifiestan que este tipo de decisiones o las toman ellos solos o en conjunto con el órgano superior de la organización. 
Hacen seguimiento a las decisiones a través de los resultados que deben producirse y de los indicadores de gestión de los procesos. Igualmente, es manifiesta la postura en la gerencia de no recibir buen apoyo con datos e información para la toma de decisiones por parte de los consultados y, en consecuencia, terminan tomándolas a partir de su propio criterio y conocimiento.

Es esta una realidad en las organizaciones, refleja la forma en que las empresas viven su realidad. Pero es, al mismo tiempo, un síntoma claro de la falta de trabajo de la gerencia para enriquecer una cultura que los trabajadores reconozcan y que está intencionalmente orientada para que ellos participen permanentemente entregando información y asumiendo la responsabilidad por ella, para tomar decisiones. Es decir que no son agentes pasivos, sino que se les invita a que de manera pertinente se vuelvan actores de la toma de decisiones de su proceso, del sistema y de la empresa en general.

Es innegable que la toma de decisiones es una clara responsabilidad de la gerencia. Ella es la encargada de decidir sobre los aspectos importantes de la empresa, sobre las perspectivas futuras del negocio y las vías que permitan su consolidación.

Ese es el escenario natural de la gerencia. Ahora bien, lo definitivo aquí es que la gerencia no persista en quedarse tomando las decisiones que tienen que ver con la tarea, con la actividad, con la minucia, para eso existen los responsables de los procesos que deben rendir cuentas en un ordenado sistema. ¿La gerencia debe estar enterada de los impactos y los resultados?, por supuesto que sí. Lo que ya no es productivo es que la gerencia se quede en ese nivel y crea que todo lo sabe y por consiguiente todo lo decide. Pero tal asunto se debe reflejar en la organización y no quedarse sólo en buenas intenciones.
Debe hacer mayor conciencia que para eso constituyó y desarrolló su sistema de gestión de la calidad, para darles la oportunidad de que actúen como un verdadero sistema, para que desde los diferentes procesos les reporten mayor calidad y nivel de información, de hechos y datos para la toma de decisiones, y de esta forma potencializar su capacidad para decidir con menor nivel de incertidumbre y que la gerencia amplíe su espectro de análisis del entorno interno y externo de su negocio.

No se evidenció que la gerencia tenga un análisis ordenado y claro de los riesgos que pueden impactar, negativa o positivamente, su negocio y en consecuencia sean fundamento determinante para la gestión.

En esta categoría, si bien es cierto se manifiesta con mayor claridad algún método para la toma de decisiones, no es menos cierto que el sistema de gestión de la calidad no ha producido un impacto determinante en el desarrollo de habilidades y capacidad en la gerencia para que la toma de decisiones sea producto de un sistema metódico, permanente, que sea evidente desde los procesos y para la organización, como elemento componente fundamental de la gestión de la gerencia que sea reconocible y en consecuencia se pueda participar en él sin mayores temores o aprehensiones..

La percepción que tienen los trabajadores sobre este tema es medianamente favorable, en el sentido de que la toma de decisiones la interpretan orientada a lograr los objetivos de la empresa, asunto que se ve como lógico, y cuando se afirma que a los trabajadores se les permite tomar decisiones relacionadas con su trabajo en particular.

Tal percepción es menos favorable cuando se indaga sobre si la gerencia pide la participación de otras personas para tomar decisiones sobre los aspectos relacionados con el trabajo y sobre si la gerencia toma decisiones basadas en el análisis de información pertinente. Asunto que permite afirmar que no existe en la gerencia una 
vocación de consulta permanente a los procesos y sus actores para enriquecer la toma de decisiones, y ellos, los trabajadores, se sienten ausentes de esa posibilidad de participación.

\section{G. Orientación a resultados}

En esta materia los gerentes están centrados -de acuerdo a lo analizado en las entrevistas- en los resultados económicos y en gran medida con los relacionados en el corto plazo. Es evidente que la gerencia sigue muy preocupada por alcanzar los resultados de la venta, por el resultado comercial y del proceso productivo, el que hace posible el producto y/o el servicio. Es incuestionable que es éste un eje vital para la organización.

Allí está centrada la concentración de la energía organizacional. Se insiste en que esto no es descabellado, es más, es bueno y saludable para el negocio, lo que se ha demostrado es que no es suficiente por sí solo para que la empresa pueda sustentar resultados en el mediano y largo plazo. Seguir visualizando toda la gestión de la empresa sólo con el foco en este aspecto, con el lente único de los resultados económicos y en el corto plazo, es asumir un alto nivel de riesgo.

Más nocivo aún cuando se realiza de manera desordenada, cuando es la angustia cotidiana de la gerencia la que se traslada a la mente y a la disposición de los trabajadores, que no atinan a coordinar sus actividades y recursos para ayudar congruentemente al alcance de los resultados de índole económica.

Se sigue viendo como un asunto de caja para los gastos. Y no, como debiera ser, como un subsistema enfocado a fortalecer la productividad y competitividad de la empresa.

Esto ha producido un impacto negativo en la consolidación de las Pymes y de su proyección para escalar posiciones que les permitan competir en mejores con- diciones y no estén sujetas a los vaivenes del medio externo. Es muy tímido y tibio el análisis de la gerencia, por ejemplo, sobre qué va a ocurrir si se aprueban o no tratados de libre comercio con otros países de la región y los efectos que puedan tener en sus negocios.

Lo anterior refuerza la conclusión de que la gerencia sigue concentrada en el corto plazo y en el resultado puramente económico. La explicación ya está dada.

Como quedó ya expuesto, los resultados son los que mantienen viva una organización. La gerencia, dentro de la visión de conjunto con que debe gestionar el negocio, ha de estar focalizada siempre en que todos los elementos componentes del sistema organizacional, al actuar haciendo uso de recursos, lo haga dentro de una planificación claramente establecida para alcanzar propósitos comunes. Se evidenció que no es claro el concepto que maneja la gerencia en esta categoría.

Y no es claro, pues lo que se deduce de sus enunciados es una concentración en los resultados operativos del corto plazo, que están ligados estrechamente con el resultado económico. Como se ha mencionado en otros casos, tal enfoque no es malo, lo que ocurre a todas luces es que es incompleto e insuficiente para asegurar productividad y desarrollo en el negocio.

En algunos casos existe la tendencia a avanzar en este sentido, pero no es clara la gerencia en la concepción y construcción metódica de un sistema que se oriente con ampliado horizonte hacia ese foco.

Son el control de costos, la facturación y la rentabilidad de la empresa lo que desvela a la gerencia y allí está focalizada, de manera poco técnica y más bien desordenada, pero no se ve un trabajo que facilite tender puentes y desarrollar vasos comunicantes organizacionales que permitan enlazar los resultados de los procesos con los del sistema en general y de éste con la anhelada mejora en la rentabilidad del negocio. 
No es claro en el modelo mental de la gerencia que los resultados son intermedios o finales y dentro de ellos los hay de índole monetaria y no monetaria. Por consiguiente, no se desarrolla una gestión gerencial orientada a resultados que permita conducir al conjunto de los procesos que conforman su sistema a que cada uno de ellos tenga la claridad y consecuente capacidad para alcanzar los resultados que han sido planificados.

Reconocen que el sistema de gestión de la calidad les ha posibilitado un mayor orden y mejor control sobre los procesos misionales que sustentan los resultados de negocio, pero es concluyente que no tienen la habilidad y la capacidad metódica para realizarlo como se debiera. Reconocen en el sistema de gestión de la calidad una herramienta poderosa para enfocarse más en el control y producir mejores resultados, pero no lo están haciendo como lo conciben. Tal pensamiento no se traslada a la realidad que vive el negocio.

Es evidente que el Sistema no ha desarrollado ni ha impactado la cultura de trabajo de la gerencia para producir un estilo o un efecto trascendente en la empresa que les permita a todos las partes involucradas entenderla como un todo y que haya una clara priorización en los resultados. No sólo en uno o en los de un solo tipo (económicos), sino en todos. Es evidente que les falta metodología para que se vuelva una herramienta más inherente al trabajo. Manifiestan que los indicadores de gestión de los procesos les facilitan el control operativo y el seguimiento a los resultados que se deben lograr.

La percepción que tienen los trabajadores sobre esta categoría, de acuerdo con la tabulación de las encuestas, es apenas favorable en su conjunto, es decir, la orientación a resultados.

Tal nivel de favorabilidad comienza a mostrarse débil cuando se plantea si, "cuando los resultados de mi proceso no son los esperados, la gerencia da realimenta- ción para poderlos alcanzar", o al preguntar si, "he sido entrenado para orientar las actividades de mi trabajo hacia el logro de los resultados planeados en mi proceso". Esto muestra claramente que los trabajadores están centrados en los resultados que para ellos son los más evidentes y por los cuales se les evalúa: los resultados económicos y de corto plazo.

\section{H. Gestión del talento humano}

Del análisis de la información recopilada en las entrevistas con los gerentes se puede evidenciar con toda claridad que no están trabajando en una verdadera gestión del talento humano.

Las Pymes, concentradas totalmente en el corto plazo y con marcado énfasis en los resultados económicos, en el mejor de los casos, se han ocupado de realizar sólo algunas actividades de orden operativo relacionadas con los aspectos legales de la contratación y el cumplimiento de tareas que tienen que ver con la seguridad social, nóminas, prestaciones legales y actividades correspondientes a la desvinculación. Es decir, con temas puramente obligatorios, en los cuales están sometidos a sanciones o problemas cuando se dejan de cumplir.

Es evidente que el sistema de gestión de la calidad les ha planteado otro nivel de exigencia que busca asegurar que las personas que se vinculen o ya vinculadas a la organización sustenten y mantengan unas competencias mínimas requeridas que garanticen que las actividades y responsabilidades de los cargos se puedan llevar a cabo, con beneficio para la empresa y demás partes interesadas.

Reconocen que aunque se ha avanzado en ese sentido, mantienen grandes debilidades para lograr que esto sea así. Que se está trabajando en fortalecer los procesos de personal para que de manera metódica se orienten y mejoren el nivel de aporte al sistema de gestión de la calidad. 
El talento relacionado estrechamente con el saber y el saber hacer, que se refleja en competencias para la empresa, no está dentro del modelo mental con el cual los gerentes conducen sus organizaciones.

Los gerentes aseguran que no obstante tener perfiles para los cargos y procesos de selección, no logran garantizar que las personas que se vinculan reúnan el nivel de competencias exigidos, sobre todo en aquellos factores que trascienden el campo de conocimiento técnico y se ubican en los aspectos personales relacionados con el comportamiento y carácter necesarios, que les permita inferir buenos desempeños en el momento de la decisión de selección.

Tienen herramientas para hacer seguimiento al rendimiento de los trabajadores, pero es evidente que no están bien consolidadas y muchas veces tales herramientas y su aplicación es fuente de mayores problemas en las decisiones de personal.

Las personas que no sirven se reemplazan. Es el aforismo que se maneja en común.

Con algunas excepciones, se manifiesta que las personas que muestran rendimientos no deseados son auxiliadas con planes de capacitación o entrenamiento. No se evidenciaron planes de carrera o por lo menos cuadros de reemplazo. Los gerentes saben que esto les sería de utilidad, pero no se deciden a trabajar a fondo sobre el tema, porque siguen viendo a las personas como recursos que generan gastos y costos y que en consecuencia son de quitar y de poner, según el cristal con que se mire la problemática del negocio.

En línea con lo anteriormente expuesto, no se tiene claro qué significa en la realidad trabajar sobre el talento humano; y, si existe algún grado de conocimiento, no se consolida en propósitos que permitan trabajar de fondo y coherentemente sobre este aspecto tan importante.
Tal situación se explica -como se ha reiterado- porque la gerencia está inmersa en el corto plazo y focalizada en los temas operativos. En consecuencia, se ve a las personas como medios, como recursos que permiten aproximarse y lograr un resultado en particular en un proceso y si no se da el resultado se cambia la persona. Por supuesto que el desgaste y la pérdida de energía a través del conocimiento que se fuga son inmensos.

Los gerentes saben que este proceder es costoso, pero no lo remedian. No lo enfrentan con decisión para volcar el modelo mental más a conseguir y mantener el talento de las personas; no perciben este aspecto como una inversión que se puede capitalizar, por el contrario, lo siguen determinando como un gasto que se debe minimizar.

Y las personas al interior saben cómo piensa la gerencia y en consecuencia se limitan a realizar el mínimo esfuerzo, centrado, desde luego, en el resultado de corto plazo, en hacer la tarea encomendada sobre la cual ha recibido instrucciones precisas. Los niveles de motivación no son precisamente hacia el compromiso con los resultados de procesos y los de la organización y no saben cómo agregar valor a productos y/o servicios del negocio.

Lo que parece paradójico es que los gerentes hablan de organizaciones rentables. Claro, seguramente es así frente a los resultados de costear, producir y vender algunos productos y servicios, que se reflejan en los estados financieros. Y tal cosa parece tranquilizar y conformar a los cuerpos gerenciales para no exigirse más en este tema, para no ir decididamente más allá sobre esta categoría.

Ahora bien, lo que parece que no saben es que una organización es productiva en la medida en que logra resultados en el corto plazo, al mismo tiempo que el sistema que los produce, con la gente como factor determinante 
a la cabeza se fortalece para responder en el mediano y largo plazo de manera sostenida y sustentable.

Es evidente que el desarrollo del sistema de gestión de la calidad ha inquietado a los gerentes sobre la necesidad de enriquecer la gestión de las organizaciones con un más ordenado trabajo sobre los asuntos concernientes a las personas y sus competencias, pues tal asunto, podría fortalecer las posibilidades del negocio, pero se siguen debatiendo entre lo urgente y lo importante.

El corto plazo les amarra a los resultados económicos y la tercerización y otras formas de contratación han incidido en sus decisiones sobre la gestión humana.

El esfuerzo de la gerencia debe orientarse a nutrir el sistema organizacional con gente talentosa en su plantilla principal, que tenga potencial de aprendizaje y que, al enfocar sus talentos y competencias en lo que la empresa concibe y comunica, como lo crucialmente importante, sume valor y potencialice el sistema para avanzar por el rumbo determinado en el direccionamiento estratégico para el negocio.

De las vivencias, de las concepciones expuestas por los gerentes, se puede deducir que el sistema no ha movido hacia los escenarios requeridos la capacidad, ni las habilidades de la gerencia, para construir pericia de gestión del talento humano que vaya más allá de las actividades operativas de la administración de las personas y que tal gestión del talento sea coherente con los propósitos de crecimiento empresarial que con alta frecuencia mencionan.

Los trabajadores de niveles tácticos, técnicos y operativos perciben apenas favorablemente la gestión del talento humano. Tal percepción disminuye cuando se afirma e investiga si, "siento que la gerencia me hace sentir como un cliente interno"; 6 , "puedo afirmar que la organización me da capacitación que se origina en las necesidades de mi proceso"; y si, "la gerencia forta- lece mis competencias para mejorar el desempeño de las actividades a mi cargo".

Es igualmente apenas favorable su percepción cuando se averiguó si, "La gerencia me alienta a mejorar el desempeño a partir de los resultados alcanzados en mi proceso", y cuando se le plantea que, "puedo afirmar que la empresa aprovecha bien los diferentes talentos que poseo como trabajador". Tal percepción es explicable, pues estas cuestiones están relacionadas más con el desarrollo y largo plazo, que con el corto plazo en que se encuentran trabajando los gerentes y las organizaciones por ellos orientadas.

\section{Mejora continua}

En esta categoría los gerentes coinciden que buscan la mejora continua a través de la implementación y seguimiento de acciones correctivas, producto de las no conformidades que detectan en su sistema. Los gerentes han concentrado su esfuerzo en trabajar en acciones correctivas producto de los problemas, resultados indeseables y no conformidades que arroja el sistema de gestión de la calidad.

Allí están concentrando su esfuerzo, sin embargo, como en otras de las categorías analizadas, tales esfuerzos son dispersos y no tienen un común denominador para los trabajadores, no tienen un eje focal que produzca un impacto más alto en la mejora del sistema, amén de la falta de capacidad organizacional para realizar un buen análisis de problemas que produzca acciones congruentes para eliminar las causas detectadas y producir efectos positivos en la supresión de tales problemas.

Así como se explicitó en la presentación de categorías, la dirección debería buscar continuamente la eficacia y la eficiencia de los procesos de la organización, más que esperar que un problema revele oportunidades para la mejora; $y$, para ayudar en el aseguramiento del futuro de la organización y la satisfacción de las partes 
interesadas, la dirección debería fomentar una cultura que involucre a las personas de manera activa en la búsqueda de oportunidades de mejora en el desempeño de los procesos, las actividades y productos.

Es decir, la gestión de la gerencia sería muy débil si sólo se orienta a esperar que surjan problemas en los procesos o con los productos para buscar posibles soluciones, detectando sus causas.

Por el contrario, como en otras de las categorías ya analizadas, se requiere de la intencionalidad de la gerencia para desarrollar toda una vocación que surge de moldear la cultura de trabajo para enfocarla hacia la mejora continua del sistema, para incrementar su capacidad de satisfacer los requisitos, necesidades y expectativas de clientes y usuarios. Esta concepción no puede ser circunstancial. Debe ser permanente en la gestión de los gerentes.

Del análisis de la información recopilada en las entrevistas con los gerentes, se puede deducir que están concentrados más en el análisis puntual de los problemas, que en buscar el desarrollo de tal vocación, que genere un fuerte arraigo y conciencia hacia la verdadera mejora.

Como quedó expuesto en el análisis de las categorías, producto de las investigaciones y del enriquecimiento de la visión sistémica, se encontró que los sistemas siempre tienden al desorden, mostrando una alta tendencia a la entropía. Una adecuada gestión de la gerencia debe reconocer estos estados y trabajar metódicamente, para encauzar el sistema organizacional por los caminos diseñados mediante la aplicación de herramientas que lo hagan posible.

Desde luego no puede desconocerse que lo expuesto por los gerentes es un avance por el camino adecuado. Es un paso importante en el sentido correcto. Pero son avances que frente a la rapidez con que evoluciona el entorno, que obliga a las organizaciones a cambiar, también con rapidez, se tornan insuficientes y distantes de los propósitos focales del sistema de gestión de la calidad.

En consecuencia y por lo analizado anteriormente, puede deducirse que el sistema de gestión de la calidad ha posibilitado un mejor entendimiento de las oportunidades que tiene la empresa cuando analiza reactivamente problemas y busca soluciones para que estos no vuelvan a ocurrir.

Pero tal entendimiento no ha impactado de manera importante las habilidades y la capacidad de gestión de la gerencia, para darle un enfoque que haga surgir una cultura de trabajo que se centre en encontrar permanentemente, como vocación, mejora continua para la empresa.

Los trabajadores tienen una percepción favorable sobre lo que la organización les ha inculcado acerca de la mejora continua. Ellos reconocen que se adelantan acciones correctivas que buscan solucionar problemas. Tal percepción está en relación directa con lo que los gerentes hacen en este tema.

Esta percepción es menos favorable cuando se indaga y afirma si, "en esta organización puedo participar para ayudar a corregir lo que no funciona", y cuando se afirma si, "Puedo informar de errores en mi proceso con la seguridad de que son analizados para solucionarlos en conjunto".

Tales resultados demuestran y reafirman que la gerencia trabaja en la orientación de acciones correctivas que están inmersas en el corto plazo, asunto que no es nocivo, pero que sí, desde luego, invita a trabajar más en los verdaderos propósitos de la mejora continua que debe producir el desarrollo de un sistema de gestión de la calidad. 


\section{CONCLUSIONES GENERALES Y RECOMENDACIONES}

Luego de analizados estas nueve (9) categorías a partir de la información recopilada en las entrevistas con cada uno de los gerentes y del análisis de las encuestas aplicadas en las mismas empresas que implementaron y mantienen un sistema de gestión de la calidad bajo los lineamientos de la Norma NTC ISO 9001/2000, se concluye, a partir de la comparación y contraste de la información, que el desarrollo del sistema de gestión de la calidad en las Pymes ha posibilitado algún orden de las operaciones y de las actividades que tienen que ver con las tareas del día a día empresarial, con el corto plazo, permitiendo en ese marco de acción un mayor seguimiento sobre las operaciones planificadas.

Es evidente, de acuerdo con el análisis particular para cada categoría, que tal orden no es producto de un arreglo organizacional sistémico y en consecuencia no está articulado con un propósito general para toda la organización que refleje la existencia de un verdadero sistema.

En la mayoría de las ocasiones no se tiene conciencia suficientemente clara de estar actuando en un conjunto de procesos. Se sigue haciendo gran énfasis más en la tarea, en el trabajo individual, en el de área, sin mayor alineamiento, y no en el colectivo de procesos que es la esencia de los sistemas de calidad, que requieren una orientación decidida hacia el sistema como un todo.

Lamentablemente las organizaciones siguen anteponiendo la necesidad comercial de contar con un documento que certifica sus prácticas de trabajo a la utilidad que representa un sistema para gestionar la organización como un todo, que articule los objetivos fundamentales del negocio, para que la gerencia oriente la empresa con eficiencia y eficacia, de tal manera que las personas y demás partes interesadas perciban que existe un orden metódicamente establecido en el cual pueden participar, que es visible y entienden cómo se articula su trabajo específico con el del proceso, y desde éste con el conjunto de procesos y con el sistema organizacional como un todo.

Cuando los gerentes y los empleados entienden cómo es la empresa, qué hace, los motivos que tiene para hacerlo y visualizan la acción mediante un método explíito, flexible, para lograrlo, con frecuencia sienten que forman parte de la organización y se comprometen a apoyarla sin tanta resistencia y en consecuencia las posibilidades de alcanzar los resultados planificados se incrementan.

Los gerentes no han incorporado a su orientación tal visión. Tratan de conseguir un mejor arreglo en la estructura de negocios con procedimientos y procesos que no están suficientemente relacionados entres sí. Se privilegia el trabajo y el resultado individual que no permite la construcción de mayor integración en la empresa. Los esfuerzos se atomizan y dispersan, perdiendo capacidad por la ausencia de sentido de conjunto.

No se puede negar que la implementación del sistema de gestión de la calidad con la orientación y apoyo de una Norma Técnica como la ISO 9001 de alguna manera ha desarrollado en la gerencia una mejor disposición para avanzar en elementos primigenios de la administración. Ha producido algún avance. Tal avance se percibe bastante fragmentado aún. Ha sido resultado más de la reacción a problemas que de la concepción de precisos programas encaminados a construir una plataforma organizacional conducida con claros y articulados propósitos para toda la empresa.

En consecuencia, las buenas intenciones de la gerencia se diluyen en la angustia del corto plazo, en la operación del día a día, quedando sus aspiraciones en deseos, en intenciones que nunca se ejecutan ante la ausencia de una planificación más clara y ejecutable. 
Se sigue procediendo, no obstante el sistema certificado, más por ensayo y error, asunto que resulta de alto riesgo para las empresas. Es el cuasi modelo perceptible: el ensayo - error, el día a día operacional desarticulado, la concentración en el corto plazo, los gerentes inmersos en la operación, que, por supuesto, produce un avance intermitente de la organización, a veces se retrocede, a veces se avanza, pero en la realidad no se sabe qué está pasando con la conducción del negocio para que esto sea así y entonces corregir o reorientar el rumbo.

El sistema ha logrado producir algún grado de avance y orden en las operaciones de las organizaciones, pero definitivamente no es el suficiente, no es el que se requiere para desarrollar empresas con modelos de negocio y gestión poderosos, que sean capaces de posicionarse sin tanta vacilación, angustia y temor en el mercado.

Se evidencia que las empresas "mueven" su sistema, más afanadas por responder a las auditorías de seguimiento y certificación de los organismos que les otorgan el reconocimiento, que impulsadas por una sana vocación de fortalecer sus procesos de gerencia hacia una renovada gestión.

Trabajan más por no perder un certificado que las habilite ante la comunidad de demandantes, que inspirados por coherentes propósitos de fortalecer y catapultar sus negocios a escenarios donde los riesgos sean gestionados adecuadamente y minimizar el grado de exposición a ellos, o donde, reconociendo que la incertidumbre siempre estará presente, se puedan movilizar con un mayor grado de certeza.

Se deduce en términos generales, apoyado en el análisis particular de las categorías realizado y la construcción epistémica de la investigación, que el sistema de gestión de la calidad no ha producido un efecto en las habilidades, en las capacidades de los gerentes y en consecuencia no se percibe un modelo de gestión que pueda presentarse como plataforma concreta que sustente la actividad futura de las organizaciones en medio de una galopante globalización con todas sus asimetrías.

La gerencia de las Pymes en Bogotá, aunque ha avanzado en la mejora de su ordenamiento operativo, no ha podido construir mejores prácticas para el gobierno empresarial, como modelo de gestión, a partir de la implementación de un Sistema de Gestión de la Calidad; igualmente, es evidente y concluyente que no han facilitado el desarrollo de las personas como mecanismo para lograr la eficiencia y eficacia de su Sistema de Gestión.

Se están quedando en la superficialidad, en las buenas intenciones de los empresarios, sin pasar a constituir el motor que permita impulsar todo el sistema operacional y de producción, que asegure impactos positivos en la rentabilidad, el mejoramiento y la sostenibilidad equilibrada del negocio.

La gerencia no se la ha jugado decididamente en adoptar el concepto de calidad y el sistema que lo hace posible como un eje vertebrador de su quehacer gerencial, de tal forma que identifique a partir de ellos caminos más ciertos para llegar a encontrar cómos gerenciales para lograr los qué de la empresa, para los cuales dicen dedicar lo mejor de sus esfuerzos y aplicar importantes energías y recursos de la organización.

La decisión de la gerencia al implementar un sistema de gestión de la calidad se está quedando en la reducida visión de contar con un documento, un certificado que comercialmente les permite realizar transacciones en un mercado que cada vez resulta más ampliado por la incontenible globalización, con fuerte incremento de la competencia. 
La alta dirección debe entender que si bien es cierto un sistema de gestión de la calidad en sí mismo no es la solución a todos los problemas que viven las organizaciones, no es menos cierto que permite una importante consolidación del quehacer organizacional alrededor de un fuerte propósito común que da mayor sentido y articulación a los derroteros del negocio.

Es a partir de la claridad con que la alta dirección asuma y mantenga el proceso que se puede avanzar por caminos menos inciertos, haciendo de este un método eficaz para la conducción de la organización.

No hay atajos para la calidad. Se debe trasegar de manera completa todo su camino, con un decidido enfoque hacia el consumidor y una mejora sostenida de las actividades y procesos, para que den lugar, cada vez de forma más eficaz y eficiente, al cumplimiento de la promesa que se hace al mercado.

Se plantea como recomendación que los entes certificadores sumen mayor valor en los procesos de audi- toría, enfocándolos más hacia la mejora continua de la organización y al impacto que la aplicación útil de los requisitos y principios debe producir en la eficacia gerencial de las empresas.

En consecuencia, la preparación y competencias de quienes realizan tales procesos de auditoría debe ser mayor y su enfoque más gerencial y no solo quedarse en la evidencia de la minucia, del papeleo, que no aporta para el fortalecimiento gerencial de las organizaciones.

Igualmente, se hace una recomendación a los consultores para que sean más profesionales e idóneos en la concepción gerencial de la organización, de tal manera que ayuden a las empresas a desarrollar sistemas de gestión de la calidad que sean más útiles a los propósitos del negocio y evidencien a los asesorados la mejora que se debe producir en la capacidad de su conducción y gobierno. 